\title{
Controlling Moisture in the Roof Cavities of Manufactured Housing
}

Douglas M. Burch

Building and Fire Research Laboratory

Gaithersburg, Maryland 20899

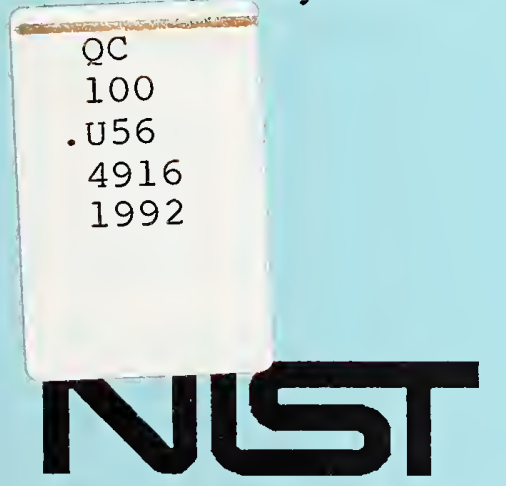

United States Department of Commerce

Technology Administration

National Institute of Standards and Technology 



\section{Controlling Moisture in the Roof Cavities of Manufactured Housing}

Douglas M. Burch

November 1992

Building and Fire Research Laboratory

National Institute of Standards and Technology

Gaithersburg, MD 20899

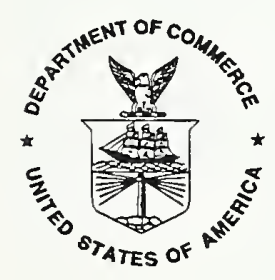

U.S. Department of Commerce

Barbara Hackman Franklin, Secretary

Technology Administration

Robert M. White, Under Secretary for Technology

National Institute of Standards and Technology

John W. Lyons, Director

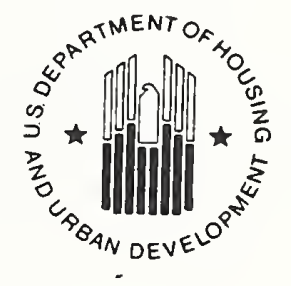

Prepared for

U.S. Department of Housing and Urban Development

Washington, D.C. 20410 
ABSTRACT

KEYWORDS

INTRODUCTION

THEORY

Governing Equations . . . . . . . . . . . . . . 3

Indoor Boundary Conditions . . . . . . . . . . . . . . . 4

Outdoor Boundary Conditions . . . . . . . . . . . . . . 4

Interface between Two Storage Layers . . . . . . . . . . 5

Non-Storage Layer . . . . . . . . . . . . . . 5

Solution Procedure . . . . . . . . . . . . . . 6

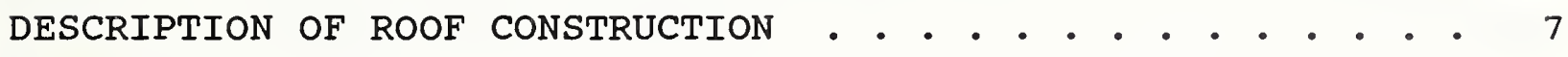

PARAMETERS USED IN ANALYSIS . . . . . . . . . . . . . . . 7

Parameters for Baseline Construction . . . . . . . . . 7

Infiltration Rate for Roof Cavity . . . . . . . . . 7

Indoor Air Exfiltration Rate into Roof Cavity . . . 8

Heat Transfer Properties . . . . . . . . . . . . 8

Diffusion Properties . . . . . . . . . . . . . . . 8

Sorption Isotherms . . . . . . . . . . . . . . . 8

Moisture Diffusivities . . . . . . . . . . . . 9

Capillary Properties . . . . . . . . . . . . . . 10

Liquid Diffusivity . . . . . . . . . . . . . 10

Capillary Pressure . . . . . . . . . . . . . 10

Unsaturated Liquid Permeability . . . . . . . . 11

Transition Properties . . . . . . . . . . . . . . 11

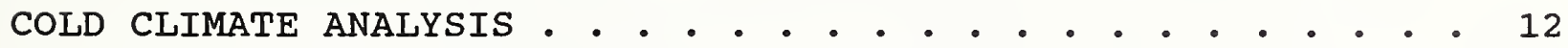

Results for Baseline Roof Construction . . . . . . . . . 12

Effect of Significant Parameters . . . . . . . . . . . 13

Outdoor climate . . . . . . . . . . . . 13

Indoor Air Exfiltration into Roof Cavity . . . . . 13

Outdoor Ventilation of Roof Cavity . . . . . . . 14

Indoor Relative Humidity . . . . . . . . . . 15

Ceiling Vapor Retarder . . . . . . . . . . . 15

Type of Roof Construction . . . . . . . . . . 15

Effect of other Parameters . . . . . . . . . . . 16

Solar absorptance of Roof . . . . . . . . . . 16

Thermal Resistance of Ceiling Insulation . . . . 16

Passive Moisture-Control Measures . . . . . . . . . 16

Plywood Roof Sheathing . . . . . . . . . . . . 17

Oriented Strand Board Roof Sheathing . . . . . . 17

Galvanized Steel Roofing . . . . . . . . . . 17 
Active Measures to Control Indoor Relative Humidity . . 18 Indoor Ventilation . . . . . . . . . . . 18 Dehumidification . . . . . . . . . . . 18

HOT AND HUMID CLIMATE ANALYSIS . . . . . . . . . . . . 18

Baseline Roof Construction . . . . . . . . . . . . 19

Naturally Ventilating the Roof Cavity . . . . . . . 19

NEEDS FOR FUTURE RESEARCH . . . . . . . . . . . 20

SUMMARY AND CONCLUSIONS . . . . . . . . . . . . 20

ACKNOWLEDGMENTS . . . . . . . . . . . . . . . . 21

NOMENCLATURE . . . . . . . . . . . . . . . 22

REFERENCES . . . . . . . . . . . . . . . . 24

\section{LIST OF TABLES}

TABLE 1 Heat Transfer Properties . . . . . . . . . . 26

TABLE 2 Empirical Constants for Sorption Isotherm Functions . 26

TABLE 3 Empirical Constants for Permeability Functions • • 26

TABLE 4 Permeances for Non-Storage Layers . . . . . . . . 27

TABLE 5 Dry Porosities and Saturated Liquid Permeabilities • 27

\section{LIST OF FIGURES}

Fig. 1. Roof construction . . . . . . . . . . . 28

Fig. 2. The sorption isotherm . . . . . . . . . . 28

Fig. 3. A non-storage layer. . . . . . . . . . 29

Fig. 4. Diffusion properties of materials used in the analysis

a. Sorption isotherms

b. Permeabilities . . . . . . . . 30

Fig. 5. Dimensionless capillary pressure versus saturation of wetting fluid for unconsolidated sands

[Collins (1961)] . . . . . . . . . 31

Fig. 6. Moisture diffusivity illustrated for sugar pine

a. Diffusivity for the moisture content gradient

b. Diffusivity for the temperature gradient . 
Fig. 7. Weekly average outdoor temperature for the four winter climates.

Fig. 8. Moisture content of plywood roof sheathing plotted versus time of year for baseline roof construction located in Madison, WI . . . . . . . . . . . .

Fig. 9. Moisture content of plywood roof sheathing plotted versus time of year for four winter climates . . . 34

Fig. 10. Moisture content of plywood roof sheathing plotted versus time of year for four exfiltration rates (Madison, WI) . . . . . . . . . . . . • • . 34

Fig. 11. Moisture content of plywood roof sheathing plotted versus time of year for four roof cavity ventilation rates (Madison, WI) . . . . . . . . . . . 35

Fig. 12. Moisture content of plywood roof sheathing plotted versus time of year for four roof cavity ventilation rates (Portland, OR) . . . . . . . . . . 35

Fig. 13. Moisture content of plywood roof sheathing plotted versus time of year for two indoor relative humidities (Madison, WI) . . . . . . . . . . . . . 36

Fig. 14. Moisture content of plywood roof sheathing plotted versus time of year for cases with and without a ceiling vapor retarder (Madison, WI)

Fig. 15. Moisture accumulation of roof plotted versus time of year for three roof constructions (Madison, WI)
a. Plywood
b. Oriented strand board
c. Galvanized steel roofing

Fig. 16. Moisture content of plywood roof sheathing plotted versus time of year for three solar absorptances (Madison, WI)

Fig. 17. Moisture content of plywood roof sheathing plotted versus time of year for two insulation levels (Madison, WI) . . . . . . . . . . . . . . . .

Fig. 18. Effectiveness of recommended practices for plywood roof construction (i.e., sealing air leakage paths in the ceiling, naturally ventilating the roof cavity, and providing a ceiling vapor retarder)
a. Madison, WI
b. Boston, MA
c. Portland, OR
c. Atlantic, GA 
Fig. 19. Effectiveness of recommended practices for OSB roof construction (i.e., sealing air leakage paths in the ceiling, naturally ventilating the roof cavity, and providing a ceiling vapor retarder) . . . . . . 40

Fig. 20. Effectiveness of recommended practices for galvanized steel roof construction (i.e., sealing air leakage paths in the ceiling, naturally ventilating the roof cavity, and providing a ceiling vapor retarder) . . . . . . . . . . . . 4 40

Fig. 21 Required mechanical ventilation rate to maintain an indoor relative humidity of $35 \%$. . . . . . . .

Fig. 22. Moisture content of kraft paper plotted versus time for baseline construction exposed to hot and humid climate (unventilated roof cavity)

a. Weekly average surface relative humidity

b. Hourly surface moisture content for July.

Fig. 23. Moisture content of kraft paper plotted versus time for baseline construction exposed to hot and humid climate (ventilated roof cavity)

a. Weekly average surface relative humidity

b. Hourly surface moisture content for July . 


\section{ABSTRACT}

A detailed computer analysis is conducted to investigate whether moisture problems occur in the roof cavity of manufactured homes constructed in compliance with the current Department of Housing and Urban Development (HUD) Standards for manufactured housing. The current HUD standards require a ceiling vapor retarder, but do not require outdoor ventilation of the roof cavity. In cold climates, the analysis revealed that moisture accumulates at lower roof surface and poses a risk of material degradation.

The analysis found the following combination of passive measures to be effective in preventing detrimental winter moisture accumulation at lower surface of the roof: 1) providing a ceiling vapor retarder, 2) sealing penetrations and openings in the ceiling construction, and 3) providing natural ventilation of the roof cavity.

In addition, the performance of a roof cavity subjected to a hot and humid climate is investigated. The analysis revealed that outdoor ventilation of the roof cavity causes the monthly mean relative humidity at the upper surface of the vapor retarder to exceed $80 \%$. This condition is conducive to mold and mildew growth.

REYWORDS: attic ventilation; HUD Manufactured Home construction and Safety Standards; manufactured housing; mobile homes; moisture control guidelines; moisture in attics

\section{INTRODUCTION}

During the winter, the occupant activities in manufactured housing release moisture to the indoor air. This causes the indoor absolute humidity to be considerably higher than that of the outdoor air. The vapor pressure difference across the ceiling construction causes moisture to be transferred into the roof cavity by diffusion. In addition, the ceiling construction also contains air leakage sites associated with lighting fixtures and other elements. The stack effect causes moist indoor air to exfiltrate through the ceiling construction and accumulate beneath the roof surface.

The moisture content of roof sheathing has not been studied in manufactured housing. However, Harrje, et al. (1984) measured the moisture content of roof sheathing of a conventional house in Princeton, NJ. Harrje found that the north-sloping roof sheathing adsorbed water vapor during winter periods and-reached a high moisture content of $20 \%$ during mid winter. When the outdoor temperature rose in the spring, the moisture content of the roof sheathing dried out and decreased to a low value of $5 \%$. 
Relative to the above discussion, the maximum amount of moisture that can be stored in roof sheathing is denoted by "fiber saturation." Above fiber saturation, liquid water appears in the pore structure of the material. Fiber saturation is generally regarded as the maximum amount of moisture that can be taken on without degradation.

Higher roof sheathing moisture contents are likely to occur in manufactured houses compared to conventional houses. Manufactured houses tend to have higher indoor relative humidity compared to conventional houses because they have smaller volumes and lower rates of natural infiltration. In addition, the Department of Housing and Urban Development (HUD) Manufactured Home Construction and Safety standards ${ }^{1}$ (1987) do not currently require ventilation openings in the roof cavity. As a result, many manufactured houses are constructed without ventilation openings.

A few field surveys documenting moisture problems in the roof cavity of manufactured housing are reported in the literature. For example, Zieman and Waldman (1984) conducted a field survey of 49 manufactured houses located in different parts of the United States which had unresolved moisture problems. Twenty-nine percent of the houses surveyed had roof cavity condensation problems, evidenced by stains at the interior surface of ceiling boards. In addition, Lee (1987) surveyed 65 manufactured houses in Alberta, Canada and reported that condensation was a problem in the roof cavity.

\section{THEORY}

A composite roof construction comprised of $\mathrm{N}$ layers in series (see fig. 1) that stores both heat and moisture is analyzed. Initially, each layer has an arbitrary moisture content. The exterior surface of the construction is then exposed to an ambient environment with time-varying temperature and relative humidity. The variation in moisture content and temperature within each of the layers is sought as a function of time. The following assumptions are used in the analysis:

- The driving forces for moisture transfer are the gradients in the moisture content and temperature.

- Heat and moisture transfer is one-dimensional.

- The heat transfer properties are constant (i.e., not a function of temperature or moisture content).

1 For the sake of brevity, The HUD Manufactured Home Construction and safety Standards will henceforth be referred to as the HUD standards. 
- The sorption isotherm is based on the average of adsorption and desorption data. Hysteresis and temperature effects on the sorption isotherm are neglected.

- The effects of temperature and hysteresis on the relationship between suction pressure and moisture content are neglected.

- Vapor adsorption at a surface releases the latent heat of vaporization and vice versa.

Additional assumptions are introduced in the development which follows.

\section{Governing Equations}

Within each layer, moisture transfer is governed by the following conservation of mass equation ${ }^{2}$ :

$$
\frac{\partial}{\partial y}\left(D_{\gamma}(\gamma, T) \frac{\partial \gamma}{\partial y}\right)+\frac{\partial}{\partial y}\left(D_{T}(\gamma, T) \frac{\partial T}{\partial y}\right)=\frac{\partial \gamma}{\partial t}
$$

The selection of moisture content $(\gamma)$ and temperature $(T)$ as potentials has the advantage that the same mathematical formulation includes both diffusion transfer and capillary transfer. As will be demonstrated later, this formulation is equivalent to using the gradient in vapor pressure as the moisture transfer potential in the diffusion regime and suction pressure in the capillary flow regime with a single required diffusivity.

Heat transfer is governed by the conservation of energy equation:

$$
\frac{\partial}{\partial y}\left(k(\gamma, T) \frac{\partial T}{\partial y}\right)=\rho\left(C_{d}+\gamma C_{w}\right) \frac{\partial T}{\partial t}
$$

The latent transport of heat is included in the boundary conditions, as will be discussed later. The term $\left(C_{d}+\gamma C_{w}\right)$ includes the effect of energy storage in both the dry material and accumulated moisture. The effect of accumulated moisture can be important (e.g., the specific heat of wood is increased by $69 \%$ after it adsorbs moisture from air at a relative humidity of $100 \%$ ).

In the two governing equations above, strong couplings exist between heat and moisture transfer. Both the diffusivity for the moisture gradient $\left(D_{\gamma}\right)$ and the diffusivity for the temperature gradient $\left(D_{\mathrm{T}}\right)$ are strong functions of moisture content and temperature. The thermal conductivity $(\mathrm{k})$ generally has a small dependence on moisture content and temperature. For the present analysis it is assumed to be constant.

2 Symbols are defined in the Nomenclature. 
At the lower boundary of the roof construction shown in Figure 1 , the convective heat transfer from the indoor air plus the latent heat from adsorbed or desorbed water vapor is equated to heat conduction into the surface, giving:

$$
h_{i}\left(T_{i}-T\right)+\dot{n}_{i}^{\prime \prime} \lambda=-k \frac{\partial T}{\partial y} \text { at } y=0
$$

At the same boundary, the moisture transferred through an air film and paint layer is equated to moisture transferred into the surface, or:

$$
M_{e i}\left(P_{i}-P\right)=-\rho_{d} D_{\gamma} \frac{\partial \gamma}{\partial y}-\rho_{d} D_{T} \frac{\partial T}{\partial y} \quad \text { at } y=0
$$

Here, an effective conductance $\left(\mathrm{M}_{e i}\right)$ defined by:

$$
\frac{1}{M_{e i}}=\frac{1}{M_{f i}}+\frac{1}{M_{p i}}
$$

has been introduced. The effect of a thin vapor retarder, such as paint or wallpaper covering, is taken into account as a surface conductance $\left(\mathrm{M}_{\mathrm{p}}\right)$ in series with the convective mass transfer coefficient $\left(M_{f i}\right)$ associated with the air film.

In Equation (4), the sorption isotherm function (f), defined below, is used as a constitutive relation to evaluate the boundary condition.

$$
\gamma=f(\phi, T) \approx f(\phi)=f\left(\frac{P_{v}}{P_{g}}\right)
$$

A sorption isotherm is illustrated in Figure 2. The moisture content of a porous material at a relative humidity of $97 \%$ can be measured and is therefore known. Moreover, when a porous material is fully saturated with liquid water, the relative humidity within the pore structure is $100 \%$. When less than fully saturated with water, the relative humidity is less than $100 \%$ due to the presence of curved menisci within the pore structure. For the present analysis, a straight line is used to connect the moisture contents just above maximum sorption $(\phi=97 \%)$ and the state of saturation $(\phi=100 \%)$.

\section{outdoor Boundary Conditions}

Similarly, at the upper boundary of the roof construction shown in Figure 1, the boundary conditions for heat and moisture transfer are: 


$$
h\left(T-T_{0}^{\prime}\right)+\dot{n}_{0}^{\prime \prime} \lambda=-k \frac{\partial T}{\partial y} \text { at } y=L
$$

and

$$
M_{\text {eo }}\left(P-P_{0}\right)=-\rho_{d} D_{\gamma} \frac{\partial \gamma}{\partial y}-\rho_{d} D_{T} \frac{\partial T}{\partial y} \text { at } y=L
$$

These boundary conditions are evaluated in a similar fashion as those at the indoor surface given in Equations (3) and (4).

\section{Interface between Two storage Layers}

When the heat transfer at the interface between two storage layers is evaluated, the temperature is assumed to be continuous. When the moisture transfer is evaluated, the relative humidity is assumed to be continuous. The sorption isotherm function (f), illustrated in Figure 2, provides the constitutive relationship, or:

$$
\phi=f_{n}^{-1}\left(\gamma_{n}\right)=f_{n+1}^{-1}\left(\gamma_{n+1}\right)
$$

where the subscripts $n$ and $n+1$ refer to the adjoining regions. The relative humidity is continuous at an interface; the moisture content will generally be discontinuous.

\section{Non-storage Layer}

The mathematical model provides for the inclusion of non-storage layers (e.g., an air space, a glass-fiber insulation cavity, or a vapor retarder) that are sandwiched between two storage layers. In a non-storage layer, the storage of heat and moisture is neglected, the transfers are steady. A non-storage layer may be convectively coupled to indoor and outdoor air.

Consider the non-storage layer shown in Figure 3. At the interface between the non-storage layer and the adjacent storage layer above, the heat transferred through the non-storage layer plus the heat gains by convective exchange with the indoor and outdoor air and the latent heat from adsorbed or desorbed water vapor are equated to the heat conduction into the storage layer, or: 


$$
\begin{gathered}
\frac{T_{S, n-1}-T_{s, n}}{R}+\dot{V}_{i} C \rho_{a}\left(T_{i}-T_{s, n}\right)+\dot{V}_{o} C \rho_{a}\left(T_{\circ}-T_{s, n}\right)+\dot{n}_{s}^{n} \lambda \\
=-k \frac{\partial T}{\partial y} \quad \text { at } y=y_{s}
\end{gathered}
$$

For the moisture, the diffusion transfer through the non-storage layer plus the moisture gains due to convective exchange with the indoor and outdoor air are equated to the moisture transfer into the storage layer, or:

$$
\begin{gathered}
M\left(P_{s, n-1}-P_{s, n}\right)+\frac{0.622 \dot{V}_{i} \rho_{a}}{P_{a}}\left(P_{i}-P_{s, n}\right)+\frac{0.622 \dot{V}_{o} \rho_{a}}{P_{a}}\left(P_{o}-P_{s, n}\right) \\
=-\rho_{d} D_{\gamma} \frac{\partial \gamma}{\partial y}-\rho_{d} D_{T} \frac{\partial T}{\partial y} \quad \text { at } y=Y_{s}
\end{gathered}
$$

The sorption isotherm function ( $f$ ) given in Equation (6) is used as a constitutive relation in evaluating the above equation.

\section{Solution Procedure}

Using a uniform nodal spacing within each layer, Equations (1-11) were recast into finite-difference equations. An implicit solution technique was used, with coupling between the two conservation equations, to solve the equations. A FORTRAN 77 computer program, called MOIST, was prepared with a tridiagonal-matrix solution algorithm. At each time step, the calculation proceeds by first solving for the temperature distribution. The program next calculates a set of surface moisture contents, followed by a set of the interior moisture contents. Next, the program calculates a revised set of surface moisture contents and interior moisture contents based on the new values of the diffusion coefficients, and so forth. This process is repeated until convergence of the moisture contents is attained. By choosing a sufficiently small time step, the need to iterate between the temperature and moisture solutions was eliminated.

The accuracy of the numerical solution depends on both the nodal spacing and the time step. Progressively smaller nodal spacing were used to ensure that calculated results did not depend significantly on the space increment.

Later in the report, program MOIST is used to analyze the heat and moisture transfer in a roof cavity. In the analysis, a time step of one hour is used. The number of nodes was two in the gypsum board, 16 in the roof sheathing, and two in the roofing paper and asphalt shingles. The kraft paper, glass fiber insulation, and the 
air space were combined into a single non-storage layer. When the computer program ran on a 386 personal computer, equipped with a math co-processor and having a 33 Mhz clock speed, it required about 60 minutes of computer time to simulate one year of real time.

\section{DESCRIPTION OF ROOF CONSTRUCTION}

For the cold climate analysis, the roof construction shown in Figure 1 was analyzed. The thermal resistance of the insulation was taken to be $\mathrm{R}-2.5 \mathrm{~m}^{2} \cdot{ }^{\circ} \mathrm{C} / \mathrm{W}\left(14 \mathrm{~h} \cdot \mathrm{ft}^{2} \cdot{ }^{\circ} \mathrm{F} / \mathrm{Btu}\right)$. Two roof sheathing materials were considered: $12 \mathrm{~mm}$ (15/32 in) exteriorgrade plywood and $11 \mathrm{~mm}$ ( $7 \backslash 16 \mathrm{in}$ ) oriented strand board (OSB). In addition, a metal roof consisting of a single layer of $0.33 \mathrm{~mm}$ ( 0.013 in) galvanized steel was analyzed. For the hot and humid climate analysis, the thermal resistance of the insulation was changed to $\mathrm{R}-1.9 \mathrm{~m}^{2} \cdot \mathrm{K} / \mathrm{W}\left(11 \mathrm{~h} \cdot \mathrm{ft}^{2} \cdot{ }^{\circ} \mathrm{F} / \mathrm{Btu}\right)$, in order to represent current construction practice for houses sold in the southern United States.

Since the mathematical model used for the analysis was one dimensional, it could not include the effect of wood-framing members. The moisture content of the roof sheathing of actual construction would tend to be a little lower than the theoretical predictions of the present report, due to the additional storage of moisture provided by wood-framing members.

\section{PARAMETERS USED IN ANALYSIS}

\section{Parameters for Baseline Construction}

Significant features of the baseline construction shown in Figure 1 include: a ceiling vapor retarder having a nominal permeance of $5.7 \times 10^{-11} \mathrm{~kg} / \mathrm{Pa} \cdot \mathrm{s} \cdot \mathrm{m}^{2}$ (1 perm) and a roof solar absorptance of 0.7 . As previously mentioned, an insulation thermal resistance of $R-2.5$ $\mathrm{m}^{2} \cdot \mathrm{K} / \mathrm{W}\left(14 \mathrm{~h} \cdot \mathrm{ft}^{2} \cdot{ }^{\circ} \mathrm{F} / \mathrm{Btu}\right)$ was used in the cold climate analysis and $\mathrm{R}-1.9 \mathrm{~m}^{2} \cdot \mathrm{K} / \mathrm{W}\left(11 \mathrm{~h} \cdot \mathrm{ft}^{2} \cdot{ }^{\circ} \mathrm{F} / \mathrm{Btu}\right)$ in the hot and humid climate analysis. In addition, it was assumed that the ceiling roof cavity was unventilated and had an infiltration rate of $1.2 \times 10^{-5} \mathrm{~m}^{3} / \mathrm{s}$ per $\mathrm{m}^{2}\left(0.14 \mathrm{ft}^{3} / \mathrm{h}\right.$ per $\left.\mathrm{ft}^{2}\right)$. It was assumed that indoor air exfiltrated into the roof construction of $2.5 \times 10^{-5} \mathrm{~m}^{3} / \mathrm{s}$ per $\mathrm{m}^{2}\left(0.3 \mathrm{ft}^{3} / \mathrm{h}\right.$ per $\mathrm{ft}^{2}$ ). Considerations for selecting the two convection coefficients are discussed below.

Infiltration Rate for Roof Cavity. It was assumed that this cavity exchanged air with the outdoor environment at a rate of $0.25 \mathrm{ach}$. 
Multiplying by the cavity volume and dividing by the ceiling area gives a volumetric infiltration rate per unit area of ceiling of $1.2 \times 10^{-5} \mathrm{~m}^{3} / \mathrm{s}$ per $\mathrm{m}^{2}\left(0.14 \mathrm{ft}^{3} / \mathrm{h}\right.$ per $\left.\mathrm{ft}^{2}\right)$.

Indoor Air Exfiltration Rate into Roof Cavity. The ceiling of a manufactured house usually contains a light fixture in each room. During the winter, indoor air is warmer and therefore lighter than colder outdoor air. As a result, the stack effect on the indoor air causes indoor air to exfiltrate through air leakage sites around the light fixtures and other air leakage sites.

In selecting an exfiltration rate, it was assumed that the total house infiltration rate was $0.25 \mathrm{ach}$. Moreover, it was assumed that half was induced by temperature-difference (i.e., stack effect) driving force, while the remainder was induced by windspeed driving force. This 50/50 percent breakdown is consistent with measurements reported by Goldschmidt and Wilhelm (1981). Furthermore, it was assumed that about one-third of the stack effect portion exfiltrates into the attic, while the other twothirds exfiltrates through the upper portion of the walls to the outdoor environment. This gives an exfiltration rate into the roof cavity of $0.042 \mathrm{ach}$. Multiplying by the house volume and dividing by its ceiling area gives a volumetric rate per unit ceiling area of $2.5 \times 10^{-5} \mathrm{~m}^{3} / \mathrm{s}$ per $\mathrm{m}^{2}\left(0.30 \mathrm{ft}^{3} / \mathrm{h}\right.$ per $\left.\mathrm{ft}^{2}\right)$.

other parameters needed in the analysis are discussed below.

\section{Heat Transfer Properties}

The thermal conductivity, density, and specific heat for the various building materials were taken from ASHRAE (1989) and are summarized in Table 1. The glass-fiber insulation was treated as a non-storage layer having a thermal resistance of $2.5 \mathrm{~m}^{2} \cdot{ }^{\circ} \mathrm{C} / \mathrm{W}$ (14 $\left.\mathrm{h} \cdot \mathrm{ft} \mathrm{t}^{2} \cdot{ }^{\circ} \mathrm{F} / \mathrm{Btu}\right)$ in the cold climates and $1.9 \mathrm{~m}^{2} \cdot{ }^{\circ} \mathrm{C} / \mathrm{W}\left(11 \mathrm{~h} \cdot \mathrm{ft}^{2} \cdot{ }^{\circ} \mathrm{F} / \mathrm{Btu}\right)$ in the hot and humid climates. The thermal resistance of kraft paper and paint layers was neglected because these layers are very thin.

\section{Diffusion Properties}

In the diffusion regime below fiber saturation, free liquid water is not present in the pore structure. Here the term free liquid water denotes water which may be removed by body forces when a material is spun in a centrifuge. It does not include capillary condensation which is bound in the micropores of the material. Procedures are discussed below to obtain sorption isotherms and vapor diffusivities for the materials.

Sorption Isotherms. The sorption isotherm data is taken from Richards, et al.(1992) where sorption isotherm data were fit to an equation of the form: 


$$
\gamma=\frac{a_{1} \phi}{\left(1+a_{2} \phi\right)\left(1-a_{3} \phi\right)}
$$

where $a_{1}, a_{2}$, and $a_{3}$ are empirical constants determined by $a$ regression analysis of the measured data. The empirical coefficients are summarized in Table 2 , and sorption isotherm curves for the materials are given in Figure $4 \mathrm{a}$.

Moisture Diffusivities. The water-vapor diffusivities for the materials are based on permeability measurements carried out by Burch, et al. (1992). For each material, a series of permeability cup measurements were carried out. In the measurements, small relative humidity differences were imposed across the specimens. A functional relationship was established between permeability and the mean relative humidity across the specimen. Separate measurements carried out at $24^{\circ} \mathrm{C}\left(75^{\circ} \mathrm{F}\right)$ and $7^{\circ} \mathrm{C}\left(45^{\circ} \mathrm{F}\right)$ revealed that temperature had an insignificant effect on permeability. In this study, the permeability data was fitted to an equation of the form:

$$
\mu=\exp \left(a_{1}+a_{2} \phi+a_{3} \phi^{2}\right)
$$

where $a_{1}, a_{2}$, and $a_{3}$ are empirical constants determined from a fit of the measured data. The empirical coefficients are summarized in Table 3. A plot of the permeabilities for the materials is given in Figure $4 \mathrm{~b}$.

The diffusivity for the moisture gradient $\left(D_{\gamma}\right)$ and the diffusivity for the temperature gradient $\left(D_{T}\right)$ are calculated by the relations:

$$
D_{\gamma}=\frac{\mu(\phi) P_{v g}(T)}{\rho_{d} \frac{\partial f(\phi)}{\partial \phi}} \quad \text { and } \quad D_{T}=\frac{\mu(\phi) \phi \frac{\partial P_{v g}(T)}{\partial T}}{\rho_{d}}
$$

The above equations may be derived by introducing the sorption isotherm function and applying the chain rule to Fick's steady state diffusion equation with the gradient of the water-vapor pressure as the driving-force potential.

The latex paint, roofing paper and shingles, $110 \mathrm{~mm}(4.3 \mathrm{in}) \mathrm{glass-}$ fiber insulation, the kraft paper vapor retarder, and the $100 \mathrm{~mm}$ $(4.0$ in) wide air space are treated as non-storage layers. Permeances for these materials, with the exception of the kraft paper, are based on ASHRAE (1989) and are given in Table 4. The permeance of kraft paper are based on measurements given in Burch, et al.(1992). 


\section{Capillary Properties}

Capillary transfer occurs when a contiguous path of liquid exists within a porous material. As the moisture content of a material is increased above maximum sorption, the moisture content at which a contiguous path of liquid first exists is termed "irreducible saturation."

Iiquid Diffusivity. In the capillary flow regime, the liquid diffusivity in porous materials may be predicted by:

$$
D_{\gamma}=-\frac{\rho_{w} \kappa \frac{\partial P_{c}}{\partial \gamma}}{\rho_{d} v}
$$

This equation follows by applying the chain rule to Darcy's Law for liquid flow through a porous media. In the analysis, the density of water $\left(\rho_{w}\right)$ was taken to be $1000 \mathrm{Kg} / \mathrm{m}^{3}\left(62.4 \mathrm{lb} / \mathrm{ft}^{3}\right)$, and the viscosity of water (u) to be $7.25 \times 10^{-4} \mathrm{~Pa} \cdot \mathrm{s}\left(4.87 \times 10^{-4} \mathrm{lb} / \mathrm{ft} \cdot \mathrm{s}\right)$. Procedures to obtain the capillary pressure $\left(P_{c}\right)$ and the unsaturated liquid permeability $(\kappa)$ are discussed below.

Capillary Pressure. The Leverett " $j$-function" (Leverett 1941) is accepted by various authors in different fields as a generalized dimensionless functional form that may be used to correlate the capillary pressure with moisture content for many different materials. The Leverett $j$ - function is defined by:

$$
j=\frac{P_{c}}{\sigma} \sqrt{\frac{\kappa_{s}}{\epsilon_{d}}}
$$

where $\kappa_{s}$ is the liquid permeability of the porous material at a saturated moisture content and $\sigma$ is the surface tension of water, taken as $6.86 \times 10^{-2} \mathrm{~N} / \mathrm{m}\left(4.7 \times 10^{-3} \mathrm{lb} / \mathrm{ft}\right)$. Dry porosity $\left(\epsilon_{d}\right)$ and saturated liquid permeability values $\left(\kappa_{s}\right)$ used in the analysis are given in Table 5.

The Leverett $j$-function or the dimensionless capillary pressure is plotted as a function of the saturation of the wetting fluid in Figure 5. Here the saturation of the wetting fluid (S) is defined as:

$$
s=\frac{\gamma-\gamma_{i r}}{\gamma_{s}-\gamma_{i r}}
$$

The Leverett j-function was fitted to data as shown in Figure 5. 
Unsaturated Liquid Permeability.

The permeability $(k)$ is estimated by the linear relation:

$$
\kappa=\kappa_{s} S
$$

The above equation is based on the modeling work of Stanish, et al. (1985). Note that the unsaturated liquid permeability is equal to zero at irreducible saturation and equal to the saturated liquid permeability $\left(\kappa_{s}\right)$ at a fully saturated state.

The liquid diffusivity is calculated from Equation (15) using the above procedures to estimate the derivative of the capillary pressure and the unsaturated permeability. The author recognizes that this procedure provides only engineering estimates for the liquid diffusivity of materials. However, liquid diffusivity data for building materials is seriously lacking in the literature. NIST is currently measuring liquid diffusivities for building materials. As these measurement results become available, the author plans to incorporate them into the model and replace the approximate method outlined above.

Within the capillary flow regime, the diffusivity for the temperature gradient $\left(D_{T}\right)$ is calculated by Equation (14).

\section{Transition Properties}

When the moisture content of a material is between a state of fiber saturation and irreducible saturation, the material is said to be in a "transition regime." At the irreducible saturation moisture content or below, free liquid water exists but not in a contiguous path. In this regime, the capillary attraction between discrete liquid particles and pores is so strong that this liquid cannot be separated from the porous material by ordinary mechanical means, such as centrifuging or applying a pressure gradient across the material. In this regime, capillary transfer vanishes and the water vapor pressure approaches saturation.

To date, different researchers do not agree on the exact moisture transfer mechanism, especially in an isothermal situation. The present model uses moisture concentration and temperature gradients as the moisture transfer potential in this regime. The diffusivity for the moisture gradient $\left(D_{\gamma}\right)$ as a function of moisture content is estimated by joining the diffusivity curves in the diffusion and capillary regimes with a straight line (on a logarithmic scale) as illustrated in Figure 6a. The mathematical relationship for the diffusivity in the transition regime is then:

$$
D_{\gamma}=D_{m s} \operatorname{Exp}\left[\frac{\gamma-\gamma_{m s^{-}}}{\gamma_{i r^{+}}-\gamma_{m s^{-}}} \ln \left(\frac{D_{i r^{+}}}{D_{m s^{-}}}\right)\right] \text {. }
$$


In the above equation, $D_{m s-}$ is the left hand limit of diffusivity at maximum sorption and $\mathrm{D}_{\text {irt }}$ is the right hand limit of liquid diffusivity at irreducible saturation. Note that Equations (14), (15), and (19) provide a continuous model for the moisture diffusivity from a dry to a saturated state.

The diffusivity for the temperature gradient $\left(D_{T}\right)$ is calculated by Equation (14) and is illustrated in Figure $6 \mathrm{~b}$.

\section{COID CLIMATE ANALYSIS}

Model MOIST is used to predict the seasonal variation in the moisture content of the roof sheathing of the roof construction shown in Figure 1. In the analysis, the indoor temperature and relative humidity are maintained at $21^{\circ} \mathrm{C}\left(70^{\circ} \mathrm{F}\right)$ and $50 \%$, respectively, unless otherwise indicated. The use of an indoor relative humidity of $50 \%$ is warranted because manufactured homes are tighter and have lower infiltration rates and therefore tend to have higher indoor relative humidities than site-built homes. In fact, Zieman and Waldman (1984) report on manufactured homes having indoor relative humidities above $50 \%$.

The outdoor temperature, relative humidity, and solar radiation are derived from weather year for energy calculations (WYEC) hourly weather data [Crow (1981)] for a mild winter heating climate (Atlanta, GA), an intermediate winter climate (Boston, MA), a cold winter climate (Madison, WI), and a Pacific northwest climate (Portland, OR). The heating degree days for these cities are $4228^{\circ} \mathrm{C} \cdot d a y s\left(7610^{\circ} \mathrm{F} \cdot d a y s\right)$ for Madison, $3207^{\circ} \mathrm{C} \cdot d a y s\left(5773^{\circ} \mathrm{F} \cdot \mathrm{days}\right)$ for Boston, $2579^{\circ} \mathrm{C} \cdot d a y s\left(4642^{\circ} \mathrm{F} \cdot\right.$ days) for Portland, and $1706^{\circ} \mathrm{C}$.days ( $\left.3071^{\circ} \mathrm{F} \cdot \mathrm{days}\right)$ for Atlanta. Figure 7 shows weekly average outdoor temperatures for these cities.

For each simulation, the performance of the roof cavity is predicted for a 1.5 year period. Six months of weather data are used to initialize the reported 1-year simulations so that the initial moisture content and temperature would have a small effect on the results.

\section{Results for Baseline Roof Construction}

The moisture content of the plywood roof sheathing is plotted versus time of year in Figure 8 for the climate of Madison, WI. During cold winter periods, indoor moisture is transferred into the roof cavity by way of diffusion and air exfiltration through the ceiling construction. Moisture is adsorbed and accumulates at the plywood roof sheathing. During the spring, the elevated temperatures promote drying and the moisture content decreases.

The solid horizontal line depicts fiber saturation in the plywood roof sheathing. As previously mentioned, when the moisture content 
rises above fiber saturation, free liquid water exists within the pores of the material and a significant potential for material degradation exists. The moisture content of the plywood roof sheathing rises above fiber saturation for almost a three-month period. The plywood roof sheathing experiences repeated expansion and contraction cycles due to seasonal fluctuations in moisture content.

In subsequent sections, model MOIST is used to analyze the effect of various parameters on the performance of the baseline roof construction. Unless otherwise indicated, the roof sheathing is plywood and the climate is Madison, WI.

\section{Effect of Significant Parameters}

outdoor climate. The moisture content of the plywood roof sheathing is plotted versus the time of year in Figure 9 for the four winter climates. Comparing the four curves, higher moisture contents occur in colder climates. In the two coldest climates (i.e., Madison, WI and Boston, MA), the moisture content rises above fiber saturation. These results indicate that climate is a very significant parameter affecting moisture accumulation in the roof sheathing of manufactured housing.

Comparing Figures 7 and 9 , the peak moisture content lags behind the minimum winter temperature by several months. This lag is due to moisture storage within the plywood roof sheathing.

It should be pointed out that the effect of climate may be less pronounced in actual manufactured houses because the indoor relative humidity will not remain constant and will tend to decrease in colder climates as a result of increased moisture losses by window condensation and infiltration of drier outdoor air.

Indoor Air Exfiltration into Roof Cavity. The following four rates of exfiltration are considered:

\begin{tabular}{||l|c|c|}
\hline \multirow{2}{*}{ Description } & \multicolumn{2}{|c|}{ Exfiltration Rate } \\
\cline { 2 - 3 } & $\mathrm{m}^{3} / \mathrm{s}$ per $\mathrm{m}^{2}$ & $\left(\mathrm{ft}^{3} / \mathrm{h}\right.$ per $\left.\mathrm{ft}^{2}\right)$ \\
\hline Perfectly Sealed Ceiling & 0.0 & $(0.0)$ \\
\hline Well Sealed Ceiling & $1.3 \times 10^{-5}$ & $(0.15)$ \\
\hline Typical Ceiling & $2.5 \times 10^{-5}$ & $(0.30)$ \\
\hline Leaky Ceiling & $5.1 \times 10^{-5}$ & $(0.60)$ \\
\hline
\end{tabular}

A perfectly sealed ceiling is an idealization which is very difficult to achieve in practice. Considerations for selecting the 
exfiltration rate for a typical ceiling was previously discussed. It was assumed that the exfiltration rate for a well-sealed ceiling was one half that for the typical ceiling, while it was assumed that the value for a leaky ceiling to be twice that of the typical ceiling.

Figure 10 shows seasonal moisture content profiles for the plywood roof sheathing for the above four cases. The results show that air exfiltration into the roof cavity has a profound effect on the amount of moisture build-up. As the rate of air exfiltration increases, both the peak and breadth of the profiles increase. In addition, the peak moisture content for a well-sealed ceiling reaches fiber saturation for a brief period. These results illustrate the importance of sealing air leakage paths in the ceiling construction of manufactured housing.

Outdoor Ventilation of Roof Cavity. Next, model MOIST is used to investigate the effect of outdoor ventilation of the roof cavity. In the analysis, the construction has a ceiling vapor retarder and the following four cavity air exchange rates were analyzed:

\begin{tabular}{|c|c|c|}
\hline \multirow{2}{*}{ Description } & \multicolumn{2}{|c|}{ Air Exchange Rate } \\
\hline & $\mathrm{m}^{3} / \mathrm{s}$ per $\mathrm{m}^{2}$ & $\left(\mathrm{ft} \mathrm{t}^{3} / \mathrm{h}\right.$ per $\left.\mathrm{ft} \mathrm{t}^{2}\right)$ \\
\hline Perfectly Sealed Cavity & 0.0 & $(0.0)$ \\
\hline Cavity without Ventilation openings & $1.2 \times 10^{-5}$ & $(0.14)$ \\
\hline Cavity with Ventilation Openings & $8.5 \times 10^{-5}$ & $(1.0)$ \\
\hline Mechanically Ventilated Cavity & $4.2 \times 10^{-4}$ & $(5.0)$ \\
\hline
\end{tabular}

In practice, a perfectly sealed attic is an idealization which is virtually impossible to achieve. Considerations for selecting the air exchange rate for a cavity without ventilation openings was previously discussed. The air exchange rate for a cavity with ventilation openings and a mechanically ventilated cavity are based on assumed volumetric ventilation rates of 2 and 10 ach, respectively.

For the above four cases exposed to Madison, WI climate, the moisture content of the plywood roof sheathing is plotted versus time of year in Figure 11. When the construction has a ceiling vapor retarder, these results reveal that providing natural ventilation significantly reduces both the peak and breadth of the profile. In fact, the peak moisture content is maintained slightly below fiber saturation. It will be shown later that natural ventilation, used in combination with sealing air.leakage paths in the ceiling construction, maintains the peak moisture content considerably below fiber saturation. On the other hand, mechanical ventilation, used in combination with a ceiling vapor retarder, 
reduces the peak moisture content well below fiber saturation.

Figure 12 shows similar simulation results for Portland, OR. Here, it is seen that ventilation is still effective in reducing moisture accumulation in the roof sheathing. In this climate, the author was concerned that the outdoor air has higher relative humidity during the winter and therefore less drying capacity.

It should be pointed out that the above analysis assumes that providing outdoor ventilation for a roof cavity does not increase the exfiltration of indoor air into the roof cavity. TenWolde and Carll (1992) have recently shown that outdoor ventilation sometimes increase the exfiltration of indoor air into building cavities. Since air exfiltration transports considerable amount of moisture into building cavities, ventilation may in these instances be counter productive.

Indoor Relative Humidity. Separate computer runs were conducted for an indoor relative humidity of $35 \%$ and $50 \%$. The results, given in Figure 13, reveal that indoor relative humidity has an important effect on both the peak and breadth of the moisture content profile. For an indoor relative humidity of $35 \%$, the peak moisture content is maintained below fiber saturation. On the other hand, for an indoor relative humidity of $50 \%$, the moisture content is above fiber saturation for almost a 3-month period. The use of humidity control as a moisture-control measure is discussed later in the report.

Ceiling Vapor Retarder. A computer simulation was conducted without a ceiling vapor retarder in the baseline roof construction. The results of this simulation are compared to the baseline construction with a vapor retarder in Figure 14. As expected, the removal of the vapor retarder increases substantially both the peak and breadth of the profile. The HUD standards currently require a ceiling vapor retarder. The results indicate this practice should continue.

Type of Roof Construction. Model MOIST was next used to analyze the moisture build-up for three roofing materials: exterior-grade plywood, oriented strand board (OSB), and galvanized steel roofing.

Figure 15a shows the results for plywood. The solid curve depicts the moisture content of a $2.4 \mathrm{~mm}(0.094$ in) thin surface layer, while the broken curve depicts the moisture content for the remaining bulk of sheathing. The moisture content of the thin surface layer is seen to closely follow that of the interior bulk layer, thereby indicating a small gradient in moisture content across the sheathing thickness.

Figure 15b shows similar results for OSB. This figure shows the thin surface layer has a considerably higher moisture content than 
the bulk layer during the winter. During this period, a significant gradient in moisture content exists across the thickness of the OSB sheathing, thereby providing a potential for buckling and warping.

The difference in behavior for the plywood and OSB sheathing was attributed to a difference in the permeability functions for the two materials. Figure $4 \mathrm{~b}$ indicates that the permeability of plywood becomes large as the moisture content approaches fiber saturation. On the other hand, the permeability of OSB is considerably smaller. As a result, moisture at the surface of OSB is not readily transferred to its interior.

The moisture build-up at the lower surface of a galvanized steel roof is given in Figure 15c. The horizontal line depicts an estimated amount of liquid water that the metal surface can retain without dripping off the surface. ${ }^{3}$ Note that the peak moisture accumulation is about $2.1 \mathrm{~kg} / \mathrm{m}^{2}\left(0.43 \mathrm{lb} / \mathrm{ft}^{2}\right)$ which corresponds to about $2.1 \mathrm{~mm}(0.08 \mathrm{in})$ water. If this moisture accumulates as frost and abruptly melts in spring, it would drip through the fibrous insulation and puddle on the kraft paper. It is unlikely that the kraft paper could support this amount of puddled water. The gypsum board would then show stains where water leaked.

\section{Effect of Other Parameters}

Solar absorptance of Roof. Three solar absorptances of the roof were analyzed: a light color $(\alpha=0.3)$, a typical medium-color $(\alpha=$ $0.7)$, and a dark color $(\alpha=0.9)$. The results given in Figure 16 indicate that lower moisture contents occur in darker roofs since they absorbed more solar radiation and dried more quickly.

Thermal Resistance of ceiling Insulation. Two thermal resistance levels were analyzed: $\mathrm{R}-2.5 \mathrm{~m}^{2} \cdot{ }^{\circ} \mathrm{C} / \mathrm{W}\left(14 \mathrm{~h} \cdot \mathrm{ft}^{2} \cdot{ }^{\circ} \mathrm{F} / \mathrm{Btu}\right)$ and $\mathrm{R}-5.3$ $\mathrm{m}^{2} \cdot{ }^{\circ} \mathrm{C} / \mathrm{W}\left(30 \mathrm{~h} \cdot \mathrm{ft}^{2} \cdot{ }^{\circ} \mathrm{F} / \mathrm{Btu}\right)$. The results given in Figure 17 indicate that the addition of insulation has very little effect on roof moisture content.

\section{Passive Moisture-Control Measures}

The author followed the general approach of finding a combination of passive measures which would maintain the peak moisture content in hygroscopic roof sheathing and moisture accumulation at metal roofs below critical levels. The author gave preferential consideration to passive, as opposed to active measures, because passive measures seem to be more likely to remain in effect during the life of the house.

3 The maximum amount of water retained was determined by spraying water onto the bottom surfaces of several pieces of galvanized steel roofing. 
For hygroscopic roof sheathing, a critical level was deemed to be fiber saturation. For metal roofs, we deemed a critical level to be a thickness of accumulated moisture (i.e., less than $0.8 \mathrm{~mm}$ or $1 / 32$ in) judged by the author to pose little or no condensation risk to the roof construction. Passive measures also provide a lower first cost to the purchaser of the house.

The following combination of passive measures were found to maintain the peak moisture content in the three roofs below critical levels.

- a ceiling vapor retarder having a permeance less than $5.7 \times 10^{-11} \mathrm{~kg} / \mathrm{Pa} \cdot \mathrm{s} \cdot \mathrm{m}^{2}$ (1 perm);

- sealing air leakage paths in the ceiling construction and attaining an exfiltration rate into the roof cavity less than $1.3 \times 10^{-5} \mathrm{~m}^{3} / \mathrm{s}$ per $\mathrm{m}^{2}\left(0.15 \mathrm{ft}^{3} / \mathrm{h}\right.$ per $\left.\mathrm{ft}^{2}\right)$;

- providing ventilation openings in the roof cavity and achieving a natural ventilation rate of $8.5 \times 10^{-5} \mathrm{~m}^{3} / \mathrm{s}$ per $\mathrm{m}^{2}\left(1.0 \mathrm{ft}^{3} / \mathrm{h}\right.$ per $\left.f t^{2}\right)$

The current HUD Standards require a ceiling vapor retarder, but do not require compliance with the other two recommended measures. The effectiveness of the recommended measures are analyzed below.

Plywood Roof sheathing. Figure 18 shows the effectiveness of the three passive measures for plywood roof sheathing exposed to the four winter climates. In each plot, the upper curve is for a vapor retarder permeance of $5.7 \times 10^{-11} \mathrm{~kg} / \mathrm{Pa} \cdot \mathrm{s} \cdot \mathrm{m}^{2}$ ( 1.0 perm), while the lower curve is for a vapor retarder permeance of $5.7 \times 10^{-12}$ $\mathrm{kg} / \mathrm{Pa} \cdot \mathrm{s} \cdot \mathrm{m}^{2}(0.1$ perm). A lower vapor retarder permeance was analyzed to investigate its merit.

In Figure 18, the three passive measures are seen to maintain the peak moisture content considerably below fiber saturation. Since the three passive measures are very effective, it is unnecessary to obtain further reductions in the moisture content by decreasing the permeance of the vapor retarder.

Oriented strand Board Roof sheathing. Similar results for the osB roof sheathing exposed to the climate of Madison, WI, are given in Figure 19. Since moisture contents are highest in Madison, the results for Madison are only presented. These results indicate that the three passive measures maintain the peak moisture content below fiber saturation. Separate curves are given for a thin surface layer and a bulk interior layer, in order to illustrate that a gradient in moisture content still exists across the thickness of the OSB sheathing.

Galvanized steel Roofing. Similar results are given in Figure 20 for a galvanized steel roof exposed to the climate of Madison, WI. 
The peak moisture accumulation is $0.41 \mathrm{~kg} / \mathrm{m}^{2}\left(0.082 \mathrm{lb} / \mathrm{ft}^{2}\right)$ for a ceiling vapor retarder permeance of $5.7 \times 10^{-11} \mathrm{~kg} / \mathrm{Pa} \cdot \mathrm{s} \cdot \mathrm{m}^{2}(1.0$ perm). The fact that moisture accumulates above maximum surface retention for a 3-month period means that the accumulated moisture will drip downwards onto the vapor retarder. However, this amount of water corresponds to a thickness of $0.4 \mathrm{~mm}(1 / 64 \mathrm{in})$. It was believed that this amount of water poses, little or no risk, to the roof construction.

\section{Active Measures to Control Indoor Relative Humidity}

Indoor Ventilation. Following the analysis procedure given in Burch (1991), the author calculated the mechanical ventilation rate that would maintain an indoor relative humidity of $35 \%$ as a function of outdoor temperature. In the analysis, the moisture generated by occupant activities was set equal to the dilution of moisture by the combination of infiltration and mechanical ventilation. The following assumptions were made: the indoor temperature was $21^{\circ} \mathrm{C}\left(70^{\circ} \mathrm{F}\right)$, the outdoor relative humidity was $80 \%$, the rate of generation of moisture by the occupants was $1.3 \times 10^{-4}$ $\mathrm{kg} / \mathrm{s}(24 \mathrm{lb} / \mathrm{day})$, and the indoor infiltration rate was proportional to the indoor-to-outdoor temperature difference.

The results are given in Figure 21 . When the outdoor temperature is above $1.7^{\circ} \mathrm{C}\left(35^{\circ} \mathrm{F}\right)$, the required mechanical ventilation rate rises exponentially and significantly exceeds a continuous rate of $0.047 \mathrm{~m}^{3} / \mathrm{s}\left(100 \mathrm{ft}^{3} / \mathrm{min}\right)$. These results indicate that ventilation is effective in reducing indoor humidity when the outdoor temperature is cold. However, during mild winter periods, very high ventilation rates are required to maintain an indoor relative humidity below 35\% because the outdoor air has considerably less drying capacity.

Dehumidification. Tsongas and Wridge (1989) discuss the use of a dehumidifier to control indoor relative humidity in houses during the winter. They point out that a dehumidifier is ineffective in reducing indoor moisture levels much below an indoor relative humidity of $40 \%$. This is because dehumidifiers are generally not capable of operating their refrigeration coils at a sufficiently low temperature to create the required indoor relative humidity.

\section{HOT AND HUMID CLIMATE ANALYSIS}

Model MOIST was next used to predict the performance of the roof construction exposed to a hot and humid climate (i.e., Lake Charles, LA). In the analysis, the indoor temperature and relative humidity were $24^{\circ} \mathrm{C}\left(76^{\circ} \mathrm{F}\right)$ and $50 \%$, respectively. 


\section{Baseline Roof Construction}

First, roof construction in compliance with the current HUD Standards was considered. The construction given in Figure 1 was used. A kraft-paper vapor retarder is installed in the ceiling, but openings are not provided to naturally ventilate the roof cavity.

The weekly-average relative humidity at the upper and lower surfaces of the kraft-paper are plotted versus time of year in Figure 22a. At the upper surface, the relative humidity rises and reaches a peak during the summer. On the other hand, the relative humidity at the lower surface departs very little from the indoor value of $50 \%$.

The solid horizontal line in Figure 22 a depicts a critical $80 \%$ level believed to coincide with the "onset for mold and mildew growth." The International Energy Agency (1990) has recently published Guidelines and Practices (Volume 2) for preventing mold and mildew growth at building surfaces. This consensus document indicates that a monthly-mean surface relative humidity above $80 \%$ is conducive to mold and mildew growth. Note that the peak relative humidity at the upper surface of the kraft paper is below the critical 80\% level. Therefore, mold and mildew growth is unlikely to occur in an unventilated roof cavity.

The hourly moisture content at the upper and lower surfaces of the kraft paper is plotted versus time for the month of July in Figure 22b. At the upper surface, the moisture content undergoes large diurnal fluctuations. During warm day periods, moisture is transferred downwards and accumulates at the upper surface of the kraft paper which is cooled by indoor air conditioning. However, the moisture content never reaches fiber saturation (21\%), indicating that liquid water is never present. TenWolde and Mei (1985) observed similar diurnal humidity fluctuations in walls.

\section{Naturally Ventilating the Roof Cavity}

Next, model MOIST was used to develop a similar pair of plots for a roof cavity ventilated at $2 \mathrm{ach}$. The results are given in Figure 23.

The weekly-average relative humidity at the upper surface of the kraft paper rises above the critical $80 \%$ level for a 2 -month summer period (see Figure 23a). The moisture content at the upper surface sometime reaches fiber saturation (see Figure 23b). Such an environment is conducive to mold and mildew growth. It is possible that the operation of fans that ventilate the interior will cause air from the roof cavity to infiltrate and transport fungal spores to the indoors. This could result in an indoor air quality problem (i.e., musty odor). 
Based on the above results, the author recommends that roof cavities of manufactured housing not be ventilated in hot and humid climates.

\section{NEEDS FOR FUTURE RESEARCH}

The author recommends that the findings of this theoretical study be corroborated by a comprehensive experimental study prior to implementation of rule changes for the HUD standards for manufactured housing. Important aspects of this research would be to: 1) measure the seasonal variation in moisture content of the roof sheathing in two side-by-side manufactured houses: one, a current practice house; the other, an identical house with the recommended moisture-control measures implemented, 2) measure outdoor air exchange rates for a roof cavity under a range of outdoor temperature and wind speeds and establish a relationship between the net free ventilation opening and the corresponding air exchange rate, and 3) measure the indoor air exfiltration rate into the roof cavity.

\section{SUMMARY AND CONCLUSIONS}

A detailed computer analysis was conducted of the combined transfer of heat and moisture in the roof construction of manufactured housing using hourly weather data for four winter climates: a cold winter climate (Madison, WI), an intermediate winter climate (Boston, MA), a mild winter climate (Atlanta, GA), and a Pacific northwest climate (Portland, OR).

The current HUD standards for manufactured housing require that manufactures provide a vapor retarder in the ceiling construction, but they are not required to ventilate the roof cavity with outdoor air. In homes constructed to this standard, the analysis revealed that a detrimental amount of moisture accumulates at the roof sheathing of homes located in cold winter and intermediate winter climates. In plywood and oriented strand board roof sheathing, the peak moisture content during the winter rose above fiber saturation, indicating the presence of free liquid water in the pore structure of the materials. In this situation, degradation of the roof sheathing may occur. In metal roofs, a significant amount of moisture accumulates at the underside of the roof surface, which may drip downward and wet the ceiling construction.

A sensitivity analysis was conducted to determine the effect of various parameters on roof moisture accumulation in cold climates. Parameters having a significant effect on the moisture accumulation in the roof sheathing included: coldness of the climate, the air tightness and permeability of the ceiling construction, the outdoor ventilation rate of the roof cavity, indoor relative humidity, and roof type. Factors having a less important effect were: the 
thermal resistance of the ceiling insulation and the solar absorptance of the roof.

The analysis revealed that the following combination of passive practices will prevent detrimental winter moisture accumulation at the roof sheathing of manufactured housing:

1) providing a ceiling vapor retarder having a permeance of 5.7 $\mathrm{X} 10^{-11} \mathrm{~kg} / \mathrm{Pa} \cdot \mathrm{s} \cdot \mathrm{m}^{2}$ ( 1 Perm) or less,

2) sealing penetrations and openings in the ceiling construction, and

3) proving outdoor ventilation openings in the roof cavity

Until HUD conducts experiments that relate net free ventilation opening to air exchange rates for manufactured housing, it is recommended that HUD adopt the attic ventilation requirements given in the HUD Minimum Property standard for one- and Two-Family Dwellings (1982) as an interim practice. That is, the net free ventilation opening shall be equal to the ceiling area divided by 300 .

Computer simulations were also carried out to investigate the performance of a roof cavity subjected to a hot and humid climate using weather data for Lake Charles, LA. In an unventilated attic, the accumulation of outdoor moisture at a ceiling vapor retarder, cooled by indoor air conditioning, was not a problem. However, when the roof cavity was naturally ventilated, intermittent wetting of the vapor retarder occurred during warm day periods. In this situation, the monthly mean relative humidity at the upper surface of the vapor retarder rose above $80 \%$ during the summer, thereby posing a risk for mold and mildew growth. For this reason, the author recommends that the roof cavities of manufactured homes not be ventilated in hot and humid climates.

It is recommended that a comprehensive experimental study be conducted to corroborate the theoretical findings of the present study.

\section{ACRNOWLEDGMENTS}

The author would like to thank william Freeborne of the Division of Innovative Technology of the U.S. Department of Housing and Urban Development for funding this project and making many helpful suggestions during the review of the report. The author would also like to thank Felix Castillo of the National Conference of states on Building codes and standards, Inc for providing information on the construction of manufactured housing. 
Symbol Units

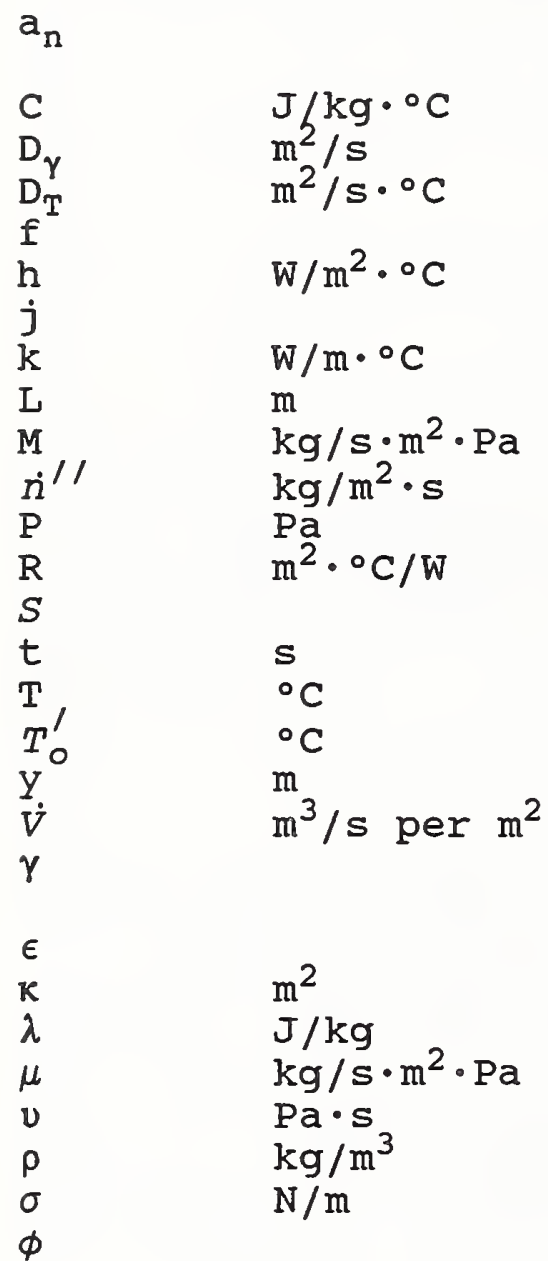

\section{Definition}

Constants in sorption isotherm and permeability function $(n=1,2$, and 3$)$

Specific heat

Diffusivity for moisture gradient

Diffusivity for temperature gradient

Sorption isotherm function

Surface heat transfer coefficient

Dimensionless capillary pressure

Thermal conductivity of porous material

Thickness of wall

Permeance or moisture conductance

Moisture mass flux

Pressure

Thermal resistance

Saturation of wetting fluid (see Equation 17)

Time

Temperature

Sol-air temperature

Distance from inside surface of wall

Volumetric air flow rate per unit area

Moisture content (ratio of wet mass to dry mass

Porosity

Unsaturated liquid permeability

Latent heat of vaporization

Water-vapor permeability

Viscosity of water

Density

Surface tension of water

Relative humidity

\section{Subscripts Refer to:}

$\mathrm{a}=$ Atmospheric or air property

c = Capillary

$\mathrm{d}=$ Dry property

e $=$ Effective property

$\mathrm{f}=\operatorname{Air} \mathrm{film}$

$g=$ Saturated state

$i=$ Indoor or inside surface property

ir $=$ Irreducible saturation

$\mathrm{ms}=$ Maximum sorption

$\mathrm{n}=$ Storage layer index

$\circ=$ Outdoor property

$\mathrm{p}=$ Paint property

$\mathrm{s}=$ Surface value or liquid saturated state

$\mathrm{T}=$ Temperature gradient 
$\mathrm{v}=$ Vapor property

$\mathrm{w}=$ Moist property

$\gamma=$ Moisture content gradient 


\section{REFERENCES}

ASHRAE. 1989. ASHRAE Handbook - 1989 Fundamentals, ch. 22. Atlanta: American Society of Heating, Refrigerating, and AirConditioning Engineers, Inc., Atlanta, GA.

Burch, D.M. 1991. "Indoor Ventilation Requirements for Manufactured Housing," NISTIR 4574. National Institute of Standards and Technology, May.

Burch, D.M.;Thomas, W.C.; Fanney, A.H. 1992. "Water Vapor Permeability Measurements of Common Building Materials," ASHRAE Transactions, Vol. 98, Part 2.

Collins, R.E. 1961. Flow of Fluids through Porous Materials. NY: Reinhold, pp. 31-33.

Crow, L.W. 1981. "Development of Hourly Data for Weather Year for Energy Calculations (WYEC)." ASHRAE Journal, Vol. 23, No. 10, October, pp. 37-41.

Department of Housing and Urban Development. 1987. "Manufactured Home Construction and safety standards." Code of Federal Regulations, Title 24, Part 3280 .

Department of Housing and Urban Development. 1992. "Minimum Property standards for One- and Two-Family Dwellings." HUD 4900.2.

Goldschmidt, V.W. and wilhelm, D.R. 1981. "Relation of Infiltration to Weather Parameters for a Mobile Home." ASHRAE Transaction, Vol. 87 , Part 2.

Harrje, D.T.; Gibson, R.G.; Jacobson, D.J.; Dutt, G.S.; and Hans, G. 1984. "Field Measurement of Seasonal Wood Moisture Variations in Residential Attics." Princeton University, Center for Energy and Environmental studies.

International Energy Agency 1990. "Guidelines and Practice." Annex XIV (Condensation and Energy), Volume 2, March.

Lee, T.G. 1987. "Condensation in Manufactured Housing." Report No. 0-88654-173-5. Alberta Municipal Affairs Housing Division, Edmonton, Alberta, Canada, February.

Leverett, M.C. 1941. "Capillary Behavior in Porous Solids." AIME Transactions, Vol. 142, pp. 152-169.

Richards, R.F.; Burch, D.M.; and Thomas, W.C. 1992. "Water Vapor Sorption Measurements of Common Building Materials." ASHRAE Transactions, Vol. 98, Part 2 . 
Stanish, M.A.; Schajer, G.S.; and Kayihan, F. 1985. Mathematical Modeling of Wood Drying from Heat and Mass Transfer Fundamentals. Drying '85, Hemisphere Publications, New York.

Tenwolde, A. and Carll, C. 1992. "The Effect of Cavity Ventilation on Moisture in Walls and Roofs." Proceedings of the ASHRAE/DOE/BTECC Conference on Thermal Performance of Exterior Envelopes of Buildings V, Clearwater Beach, FL, Dec. 7-10.

TenWolde, A. and Mei, H.T. 1985. "Moisture Movement in Walls in a Warm Humid Climate." Proceedings of the ASHRAE/DOE/BTECC Conference on Thermal Performance of the Exterior Envelopes of Buildings III, ASHRAE SP 49. Clearwater Beach, FL. Dec. 2-5.

Tsongas, G.A. and Wridge, R.S. 1989. "Field Monitoring of the winter Performance of a Residential Dehumidifier," ASHRAE Transactions, Vol. 95, Pt. 1 .

Zieman, M.L. and Waldman, J.D. 1984. "Moisture Problems in Mobile Homes." Final Report for HUD Contract H-10992, Department of Housing and Urban Development, July 10. 


\begin{tabular}{||l|c|c|c|}
\hline \multicolumn{3}{|c|}{ TABLE 1 } \\
\hline Material & $\begin{array}{c}\text { Thermal } \\
\text { Conductivity } \\
\mathrm{W} / \mathrm{m} \cdot \mathrm{K}\end{array}$ & $\begin{array}{c}\text { Density } \\
\mathrm{kg} / \mathrm{m}^{3}\end{array}$ & $\begin{array}{c}\text { Specific Heat } \\
\mathrm{J} / \mathrm{kg} \cdot{ }^{\circ} \mathrm{C}\end{array}$ \\
\hline \hline Exterior-Grade Plywood & 0.115 & 509 & 1214 \\
\hline Oriented Strand Board & 0.118 & 641 & 1298 \\
\hline Gypsum Board & 0.160 & 670 & 1089 \\
\hline
\end{tabular}

\begin{tabular}{|c|c|c|c|}
\hline \multicolumn{5}{|c|}{ TABLE 2 } \\
\hline Empirical Constants for Sorption Isotherm Functions \\
\hline Material & $a_{1}$ & $a_{2}$ & $a_{3}$ \\
\hline \hline Exterior-Grade Plywood & 0.3441 & 6.177 & 0.8283 \\
\hline Oriented Strand Board & 0.2121 & 3.427 & 0.8106 \\
\hline Gypsum Board & 0.0247 & 9.0750 & 0.93540 \\
\hline
\end{tabular}

\begin{tabular}{|c|c|c|c|}
\hline \multicolumn{4}{|c|}{ TABLE 3} \\
Empirical Constants & \multicolumn{3}{|c|}{} \\
\hline Material Permeability Functions & \\
\hline \hline Exterior-Grade Plywood & -26.662 & -6.368 & $a_{3}$ \\
\hline Oriented Strand Board & -27.679 & -1.468 & 3.418 \\
\hline Gypsum Board & -23.472 & -1.480 & 1.082 \\
\hline
\end{tabular}

1 Permeability is expressed in $\mathrm{kg} / \mathrm{Pa} \cdot \mathrm{s} \cdot \mathrm{m}$. 


\begin{tabular}{||c|c|}
\hline \multicolumn{2}{|c|}{ TABLE 4} \\
Permeances for Non-Storage Layers \\
Material & $\begin{array}{c}10^{-10} \\
\mathrm{~kg} / \mathrm{s} \cdot \mathrm{m}^{2} \cdot \mathrm{Pa}\end{array}$ \\
\hline \hline Latex Paint & 5.7 \\
\hline Roofing Paper and Shingles & Impermeable \\
\hline $110 \mathrm{~mm}$ Glass Fiber Insulation & 15. \\
\hline Kraft Paper (Asphalt Impregnated) & 0.86 \\
\hline $100 \mathrm{~mm}$ Air Space & 17. \\
\hline
\end{tabular}

\begin{tabular}{||c|c|c|}
\hline Dry Porosities and Saturated Liquid Permeabilities \\
\hline Material & $\epsilon_{\mathrm{d}}$ & $\begin{array}{c}\mathrm{k}_{\mathrm{s}} \\
\mathrm{m}^{2}\end{array}$ \\
\hline \hline Exterior-Grade Plywood & 0.636 & $2.8 \times 10^{-19}$ \\
\hline Oriented Strand Board & 0.572 & $2.8 \times 10^{-19}$ \\
\hline Gypsum Board & 0.500 & $1.1 \times 10^{-14}$ \\
\hline
\end{tabular}




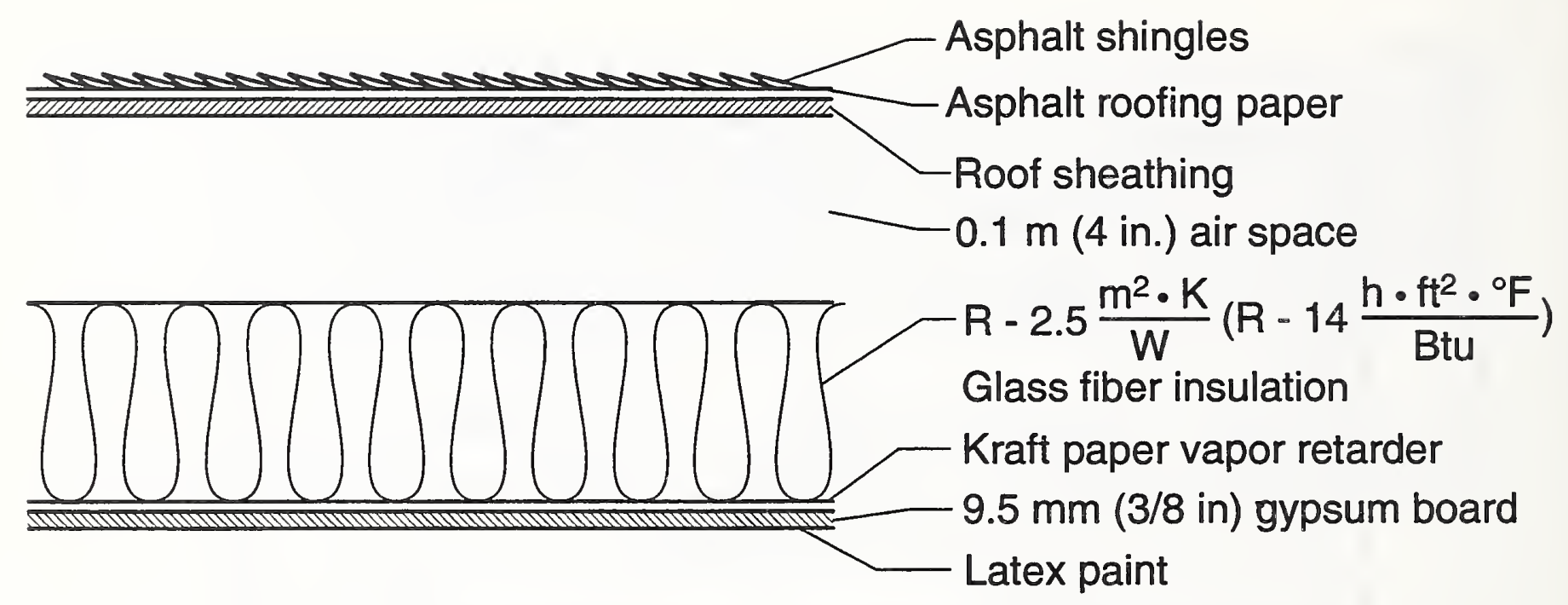

Fig. 1. Roof construction

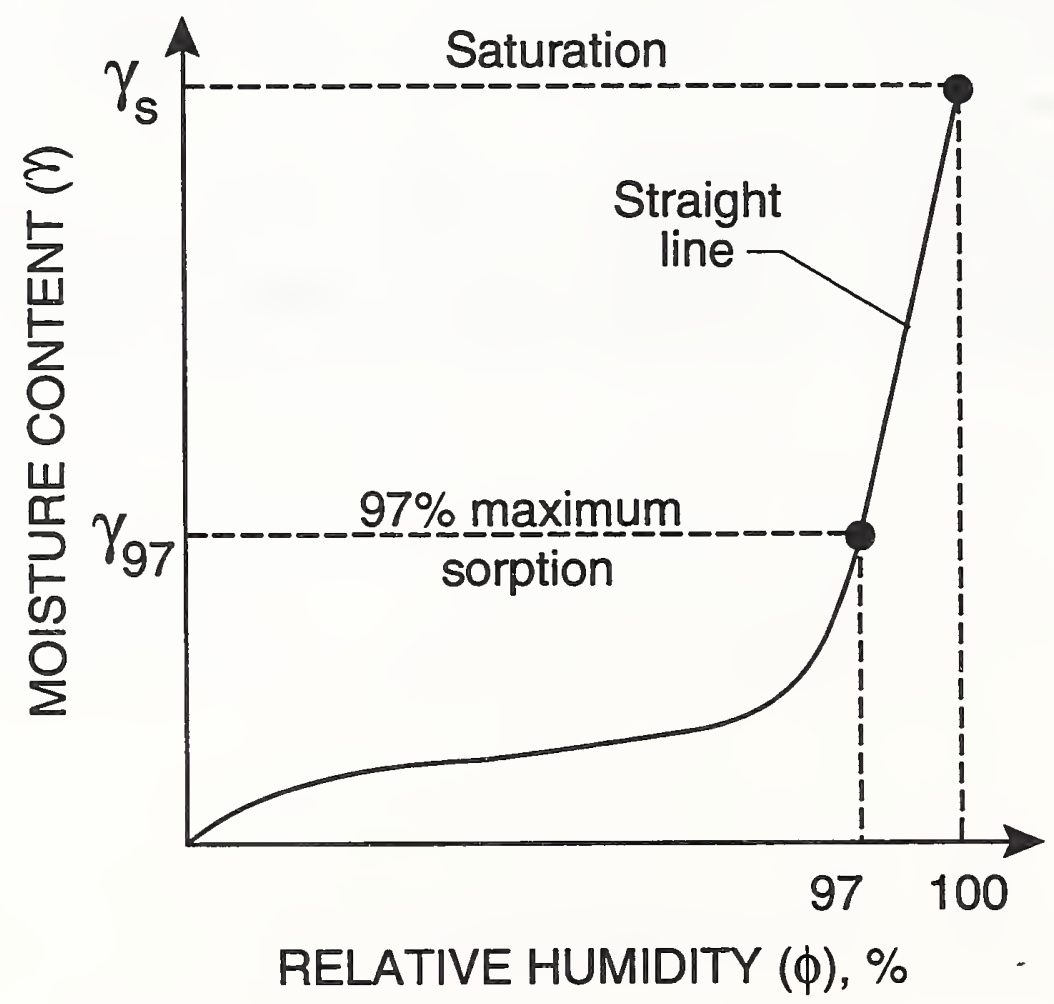

Fig. 2. The sorption isotherm 


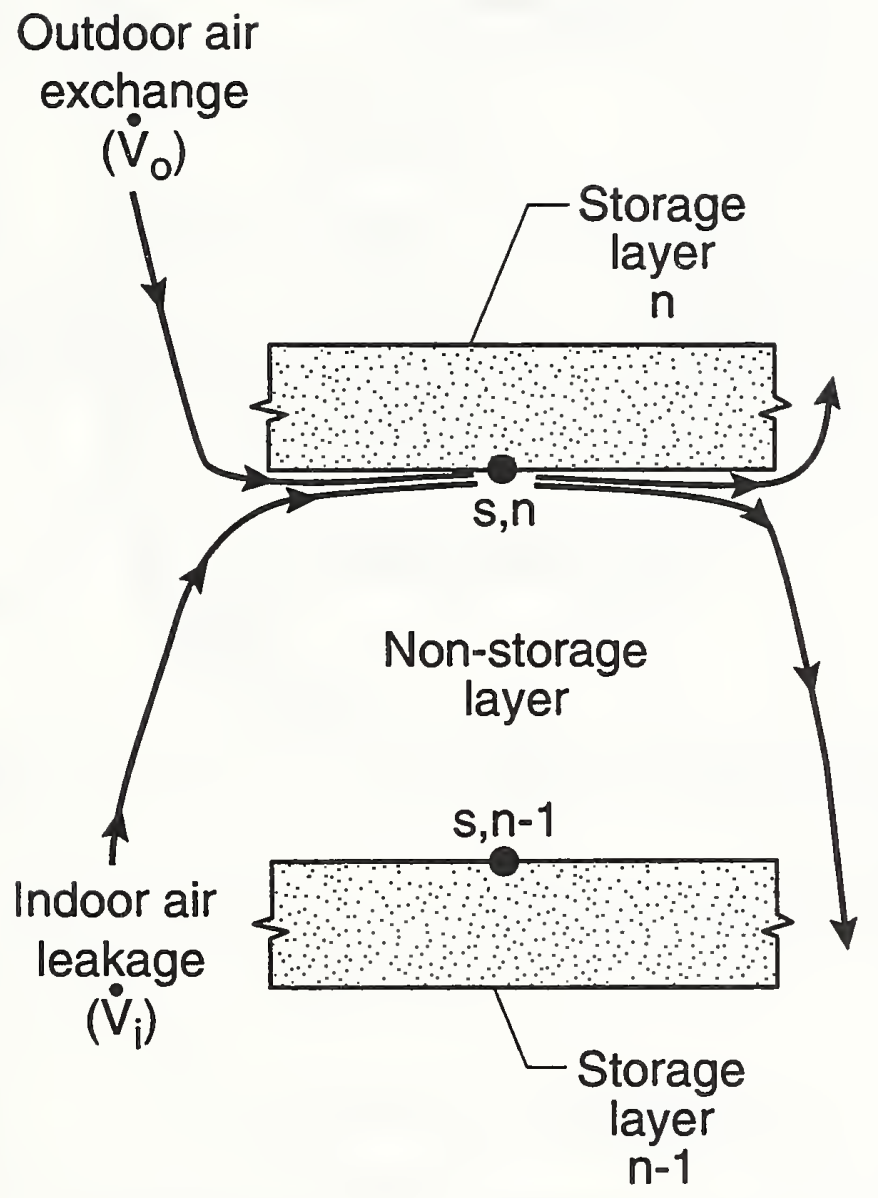

Fig. 3. A non-storage layer 


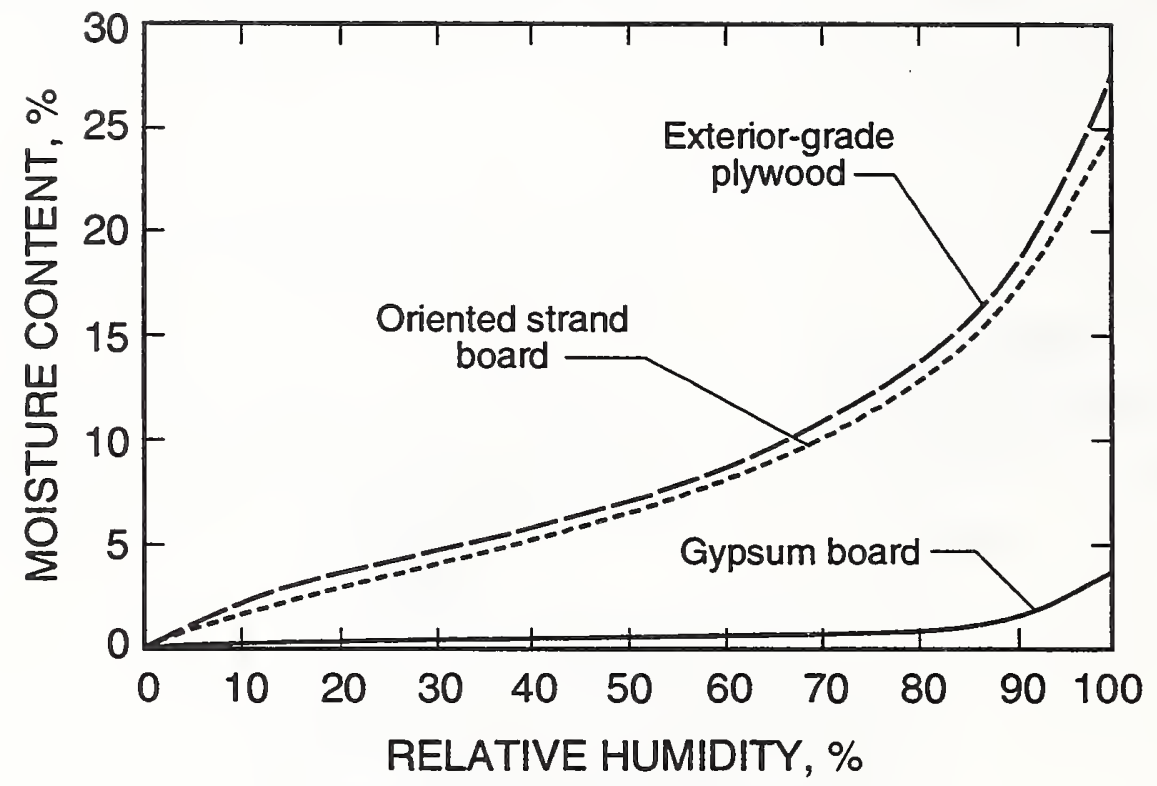

a. Sorption isotherms

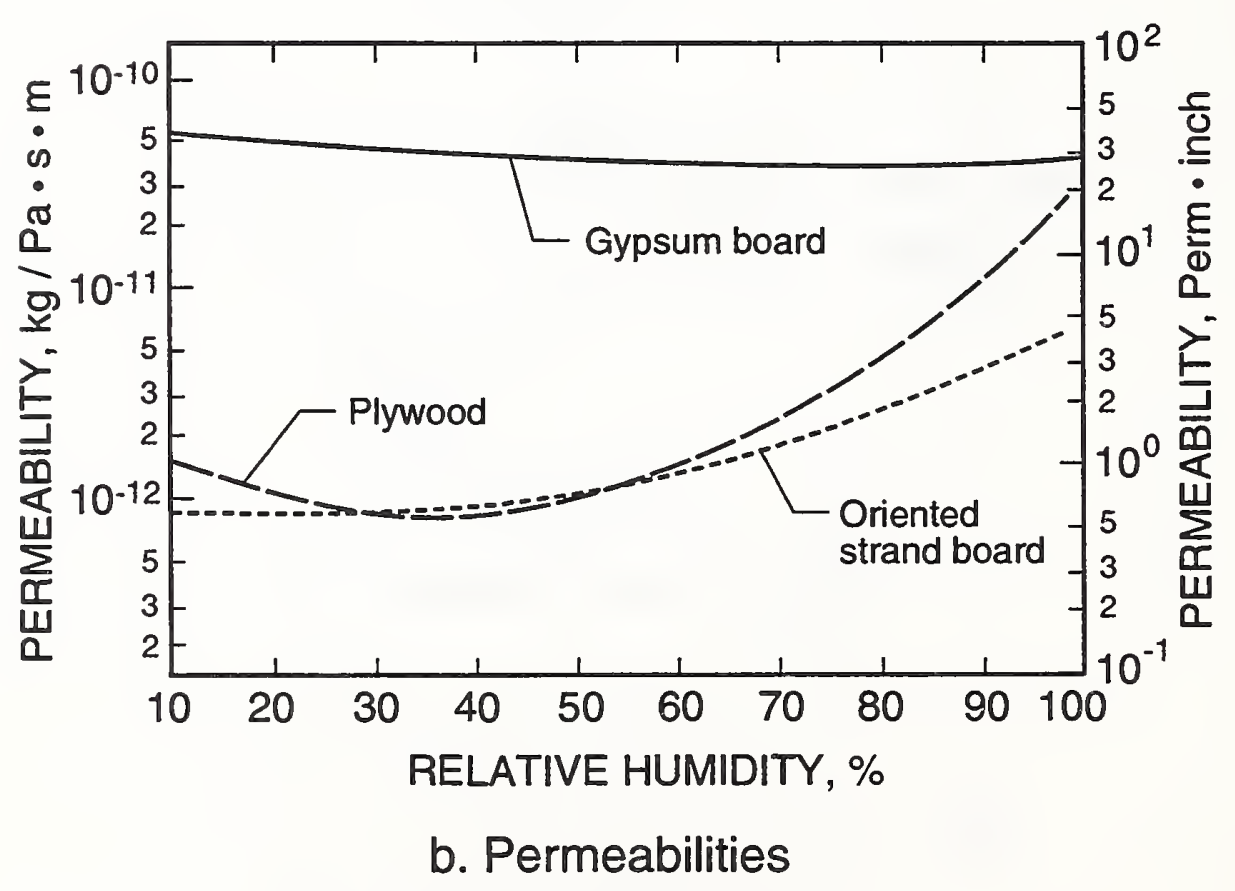

Fig. 4. Diffusion properties of materials used in the analysis 


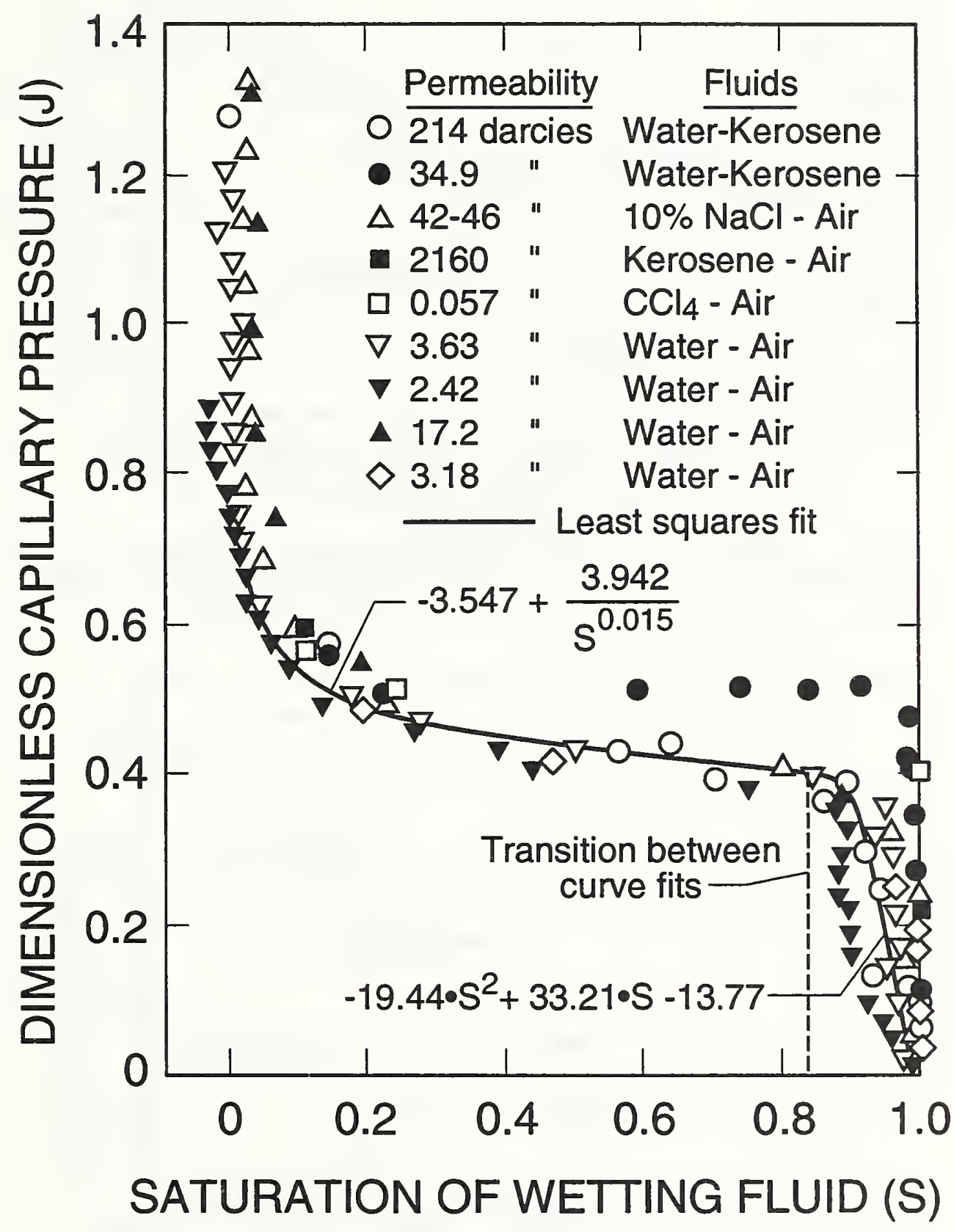

Fig. 5. Dimensionless capillary pressure versus saturation of wetting fluid for unconsolidated sands [Collins (1961)] 


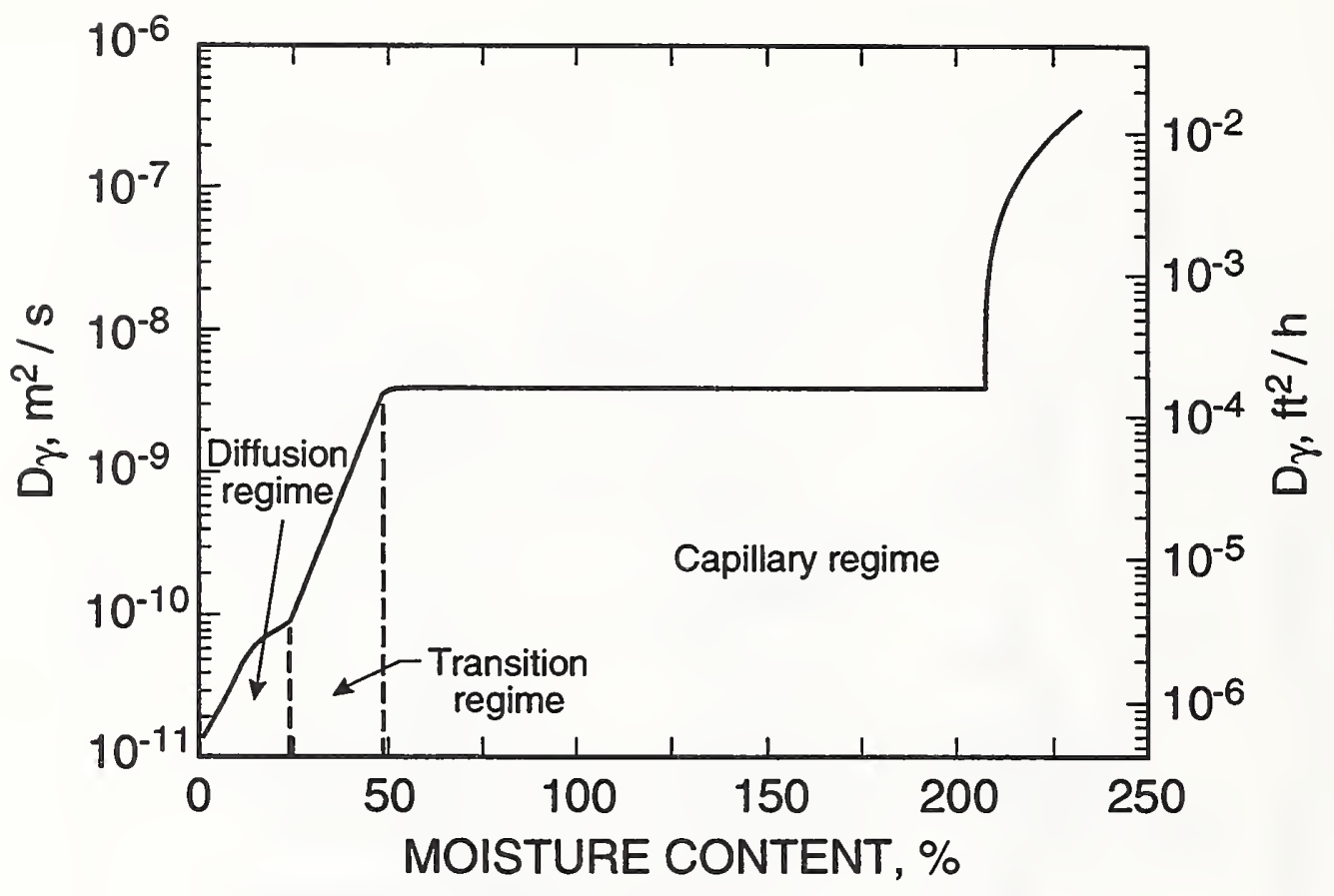

a. Diffusivity for the moisture content gradient

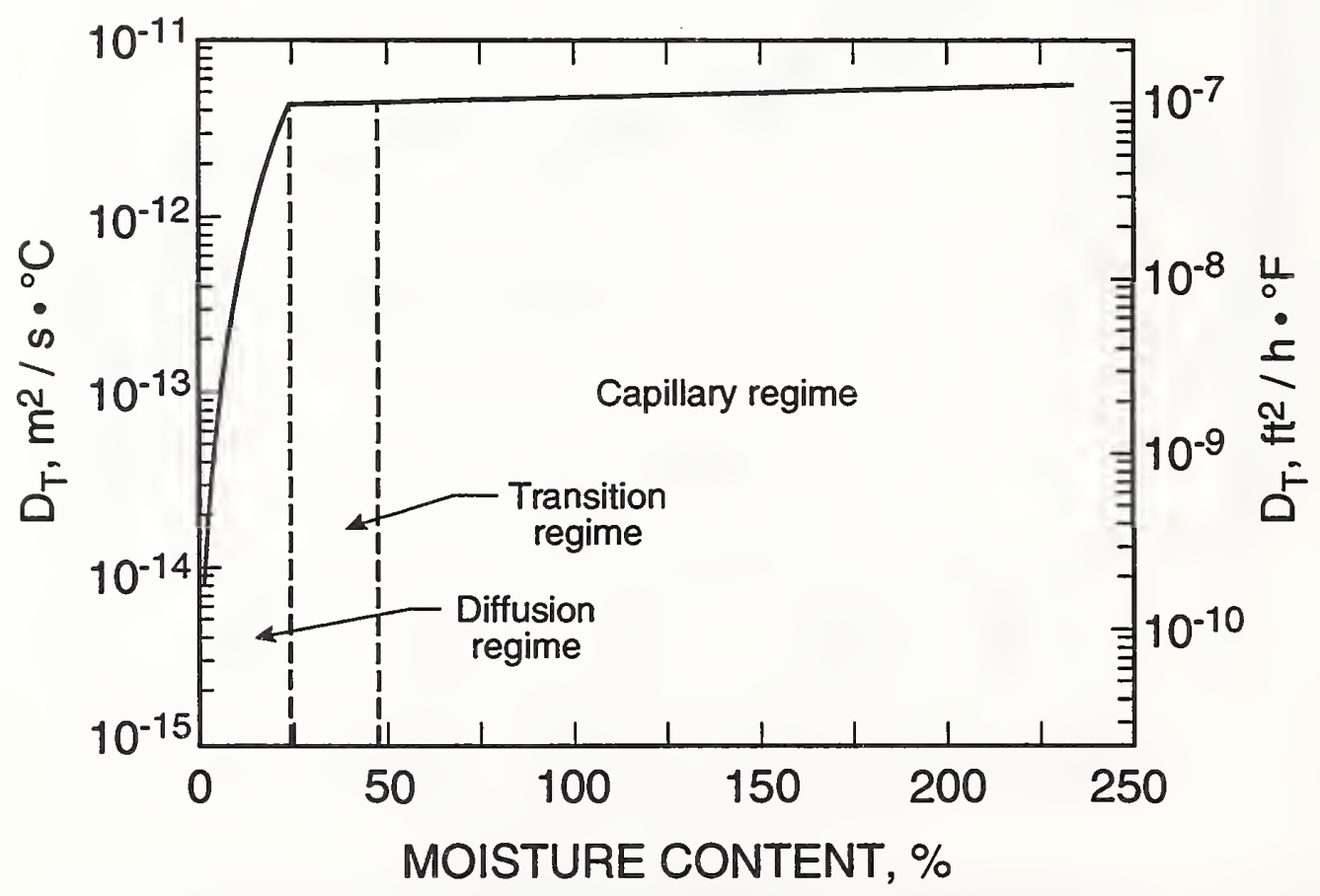

b. Diffusivity for the temperture gradient

Fig. 6. Moisture diffusivity illustrated for sugar pine 


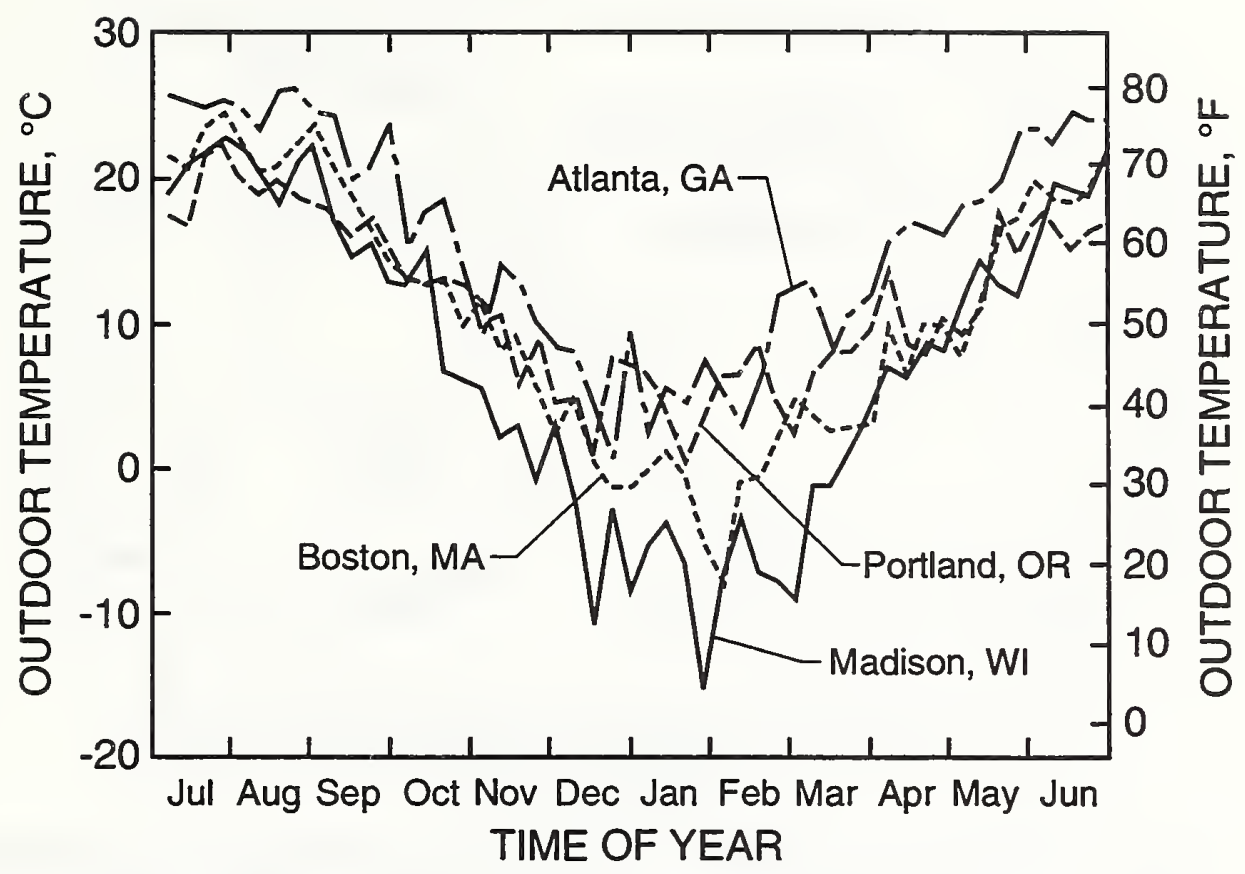

Fig. 7. Weekly average outdoor temperature for the four winter climates

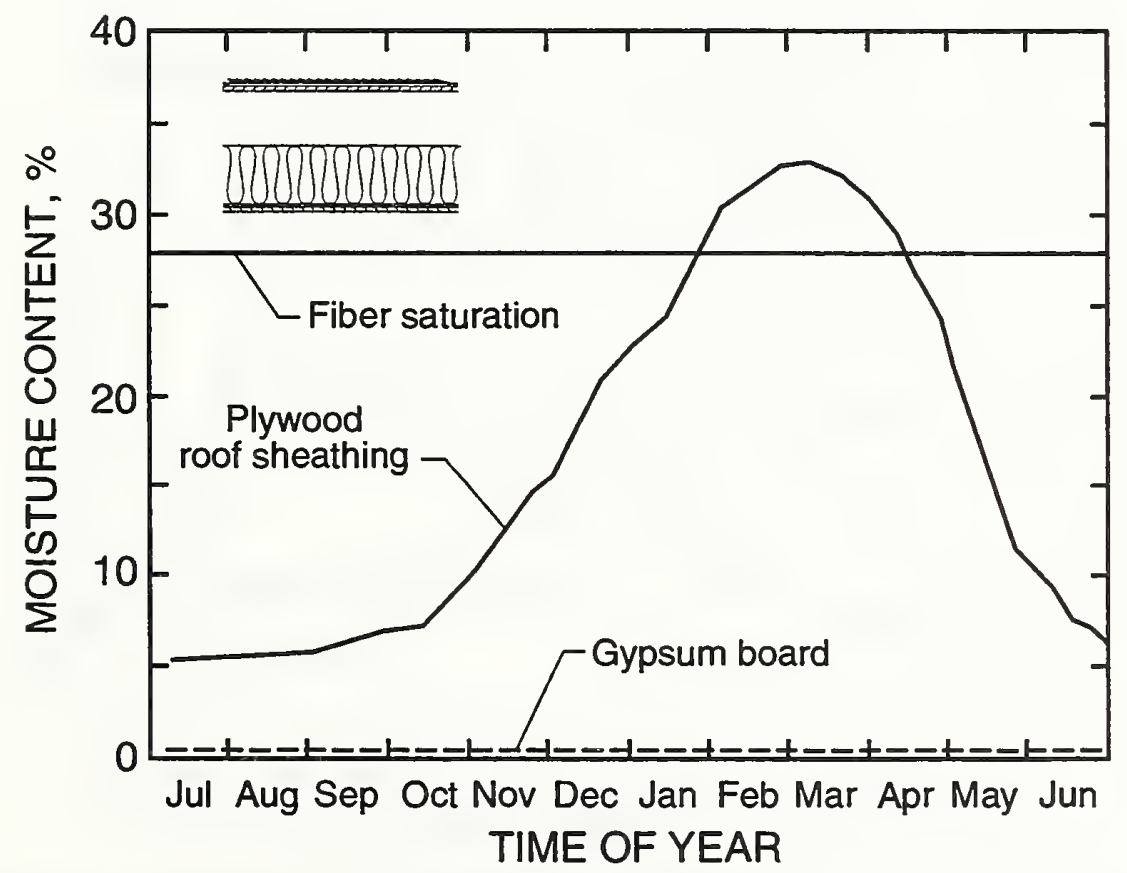

Fig. 8. Moisture content of plywood roof sheathing plotted versus time of year for baseline roof construction located in Madison, WI. 


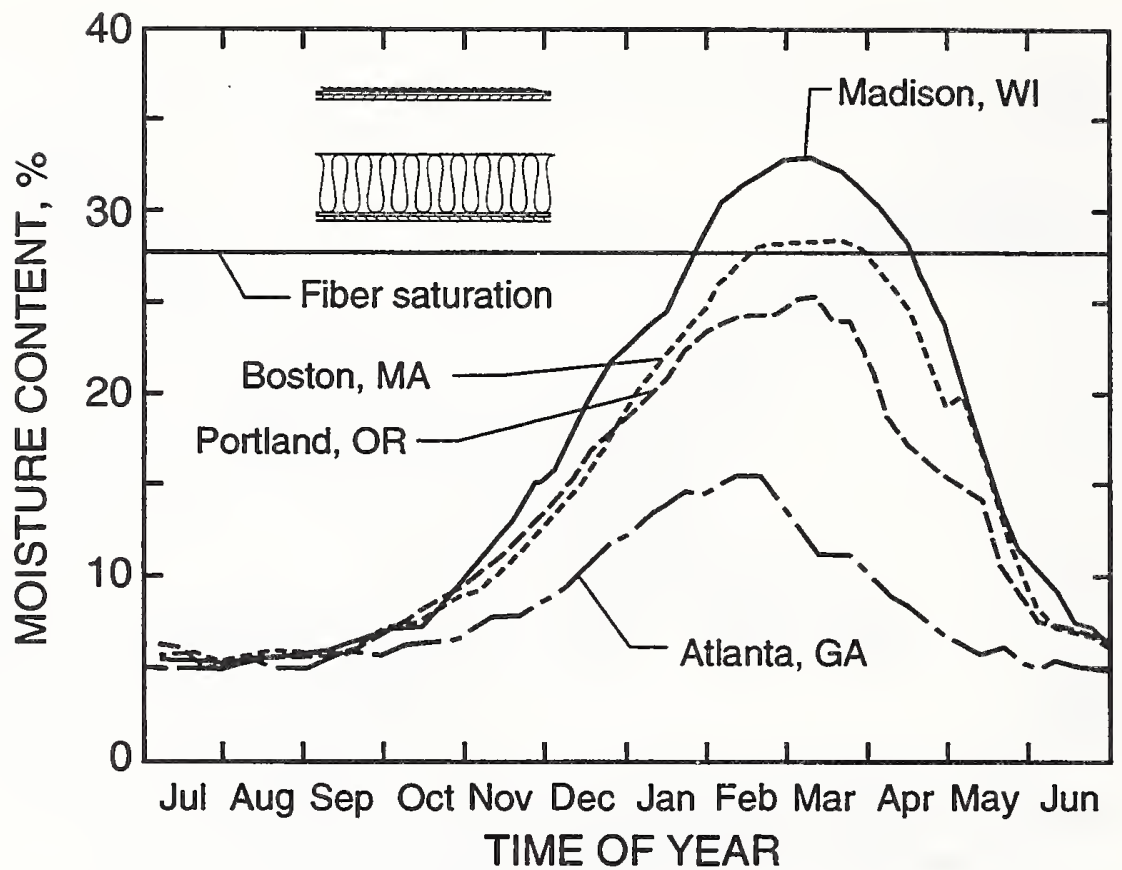

Fig. 9. Moisture content of plywood roof sheathing plotted versus time of year for four winter climates.

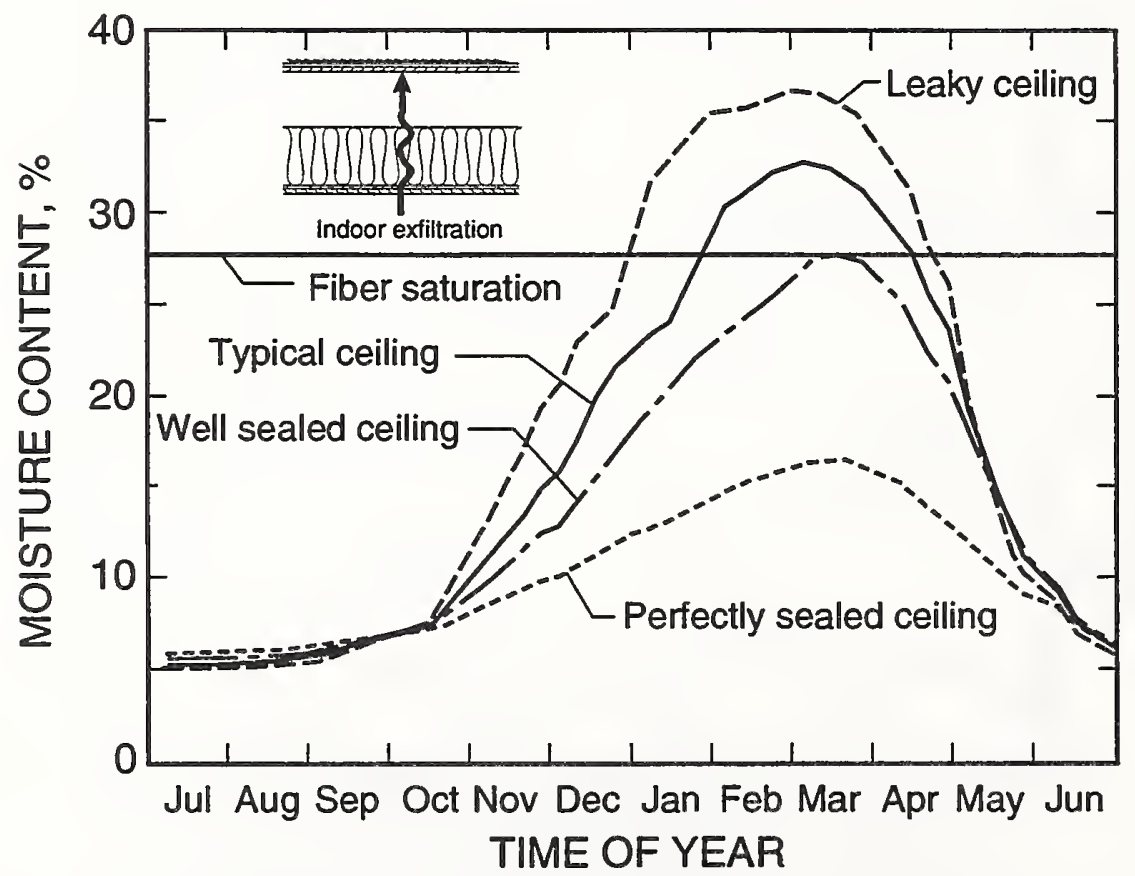

Fig. 10. Moisture content of plywood roof sheathing plotted versus time of year for four exfiltration rates (Madison, WI) 


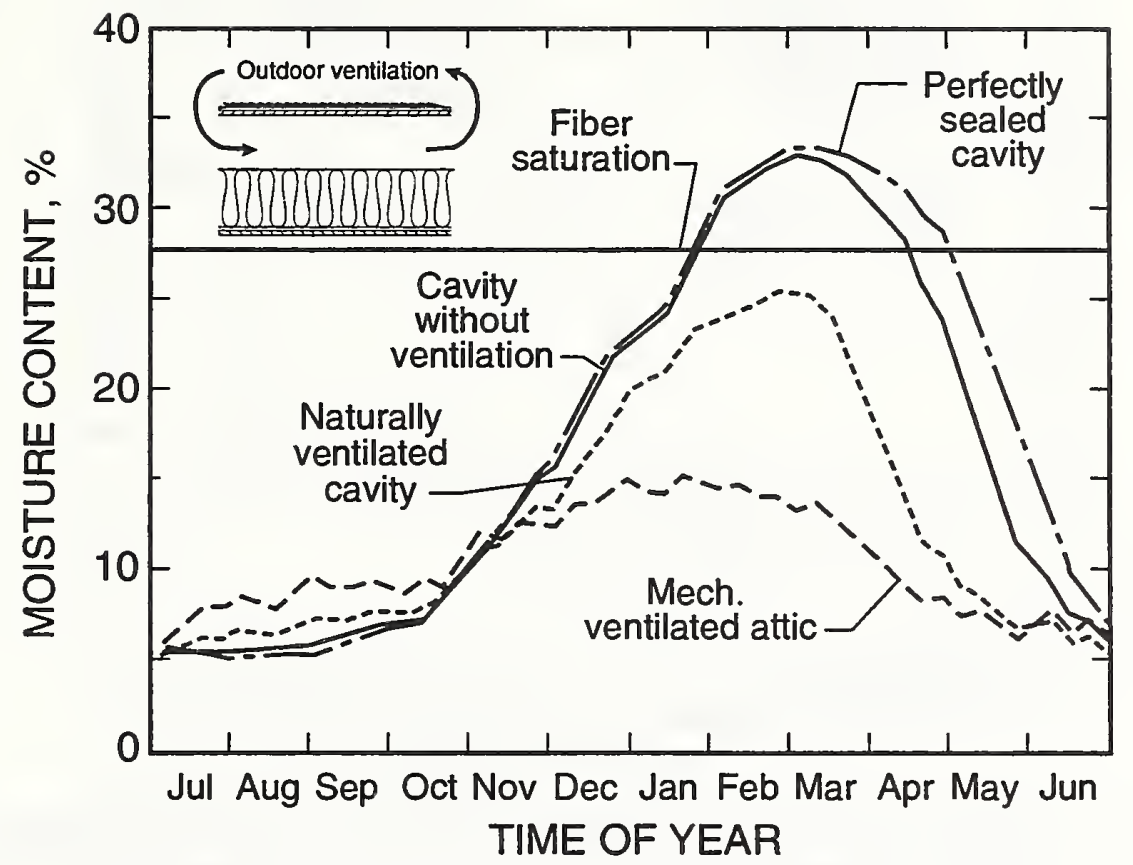

Fig. 11. Moisture content of plywood roof sheathing plotted versus time of year for four roof cavity ventilation rates (Madison, WI).

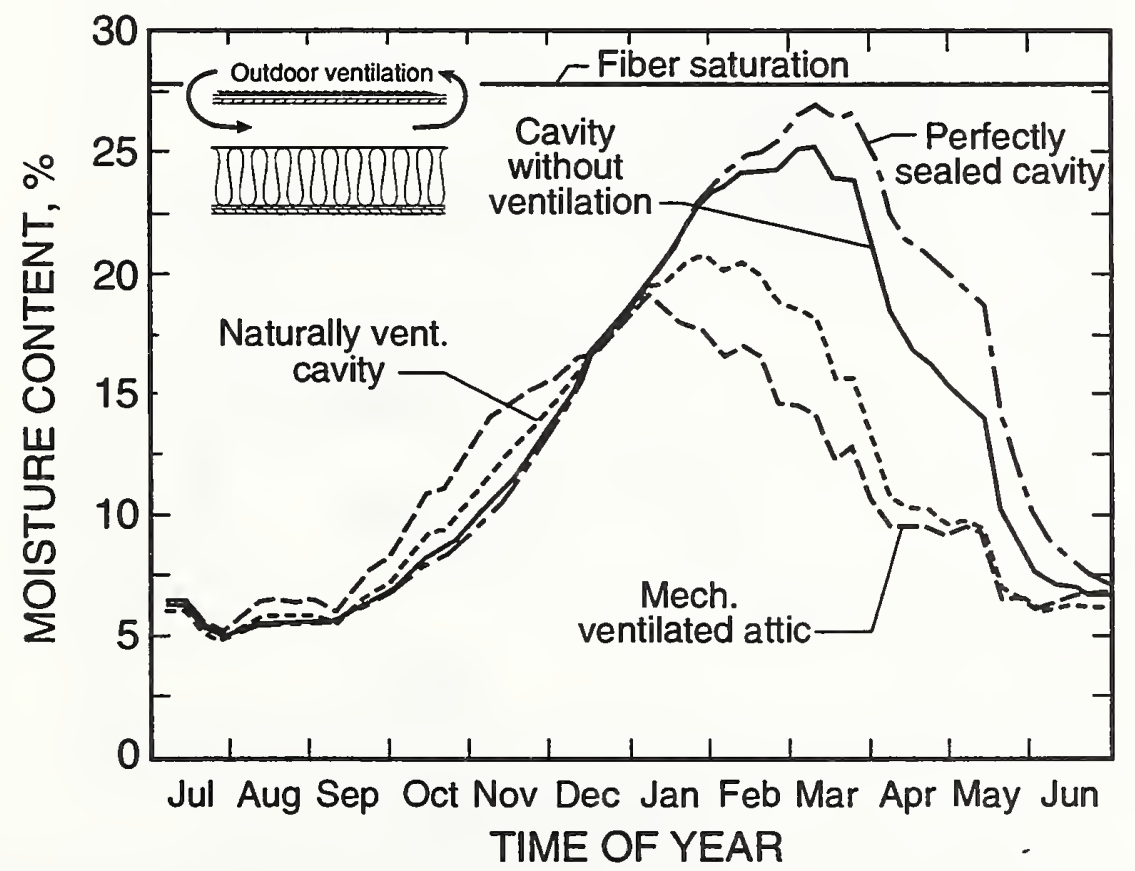

Fig. 12. Moisture content of plywood roof sheathing plotted versus time of year for four roof cavity ventilation rates (Portland, OR). 


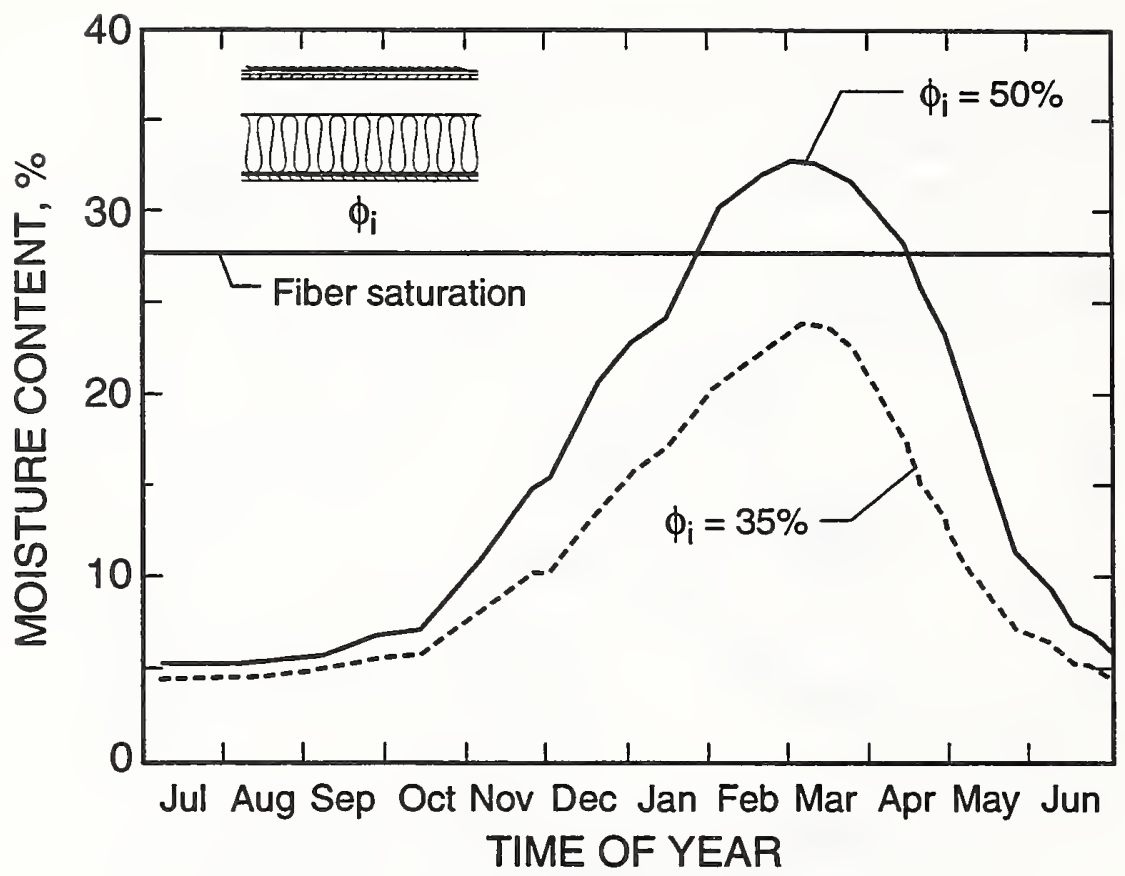

Fig. 13. Moisture content of plywood roof sheathing plotted versus time of year for two indoor relative humidities (Madison, WI).

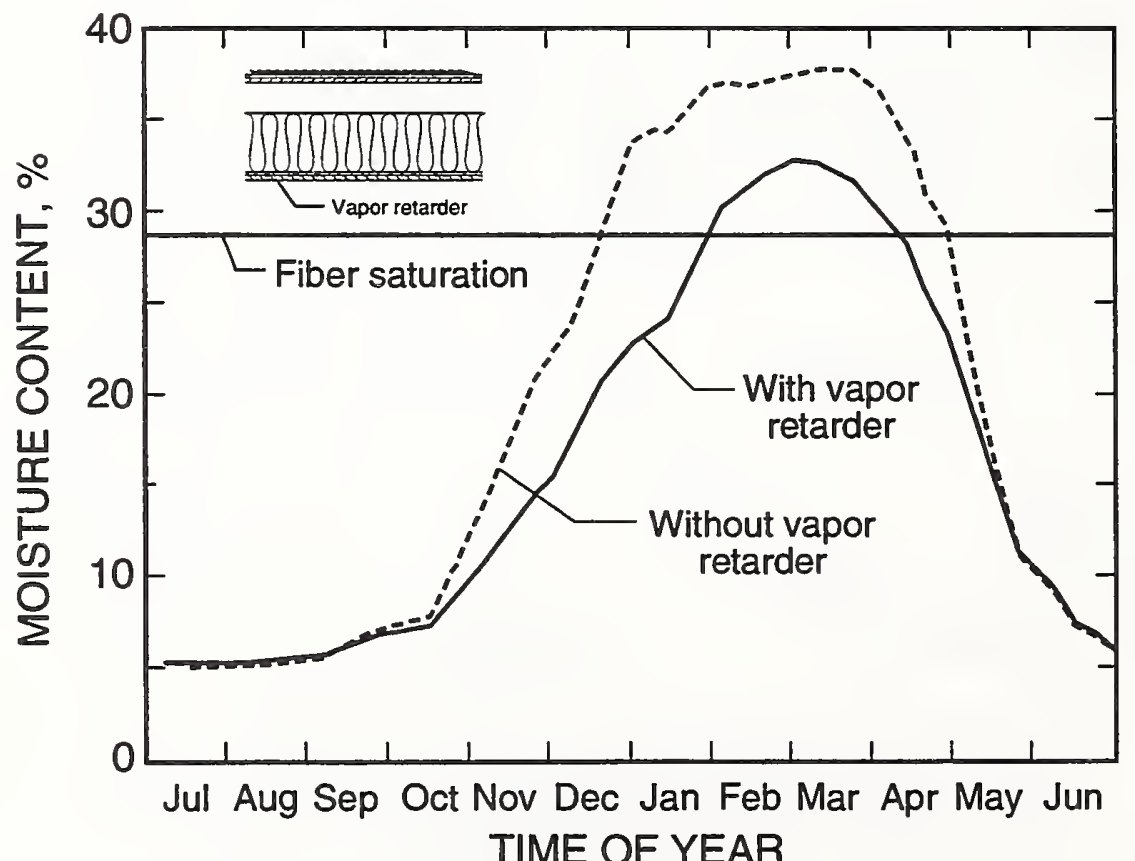

Fig. 14. Moisture content of plywood roof sheathing plotted versus time of year for cases with and without a ceiling vapor retarder (Madison, WI). 


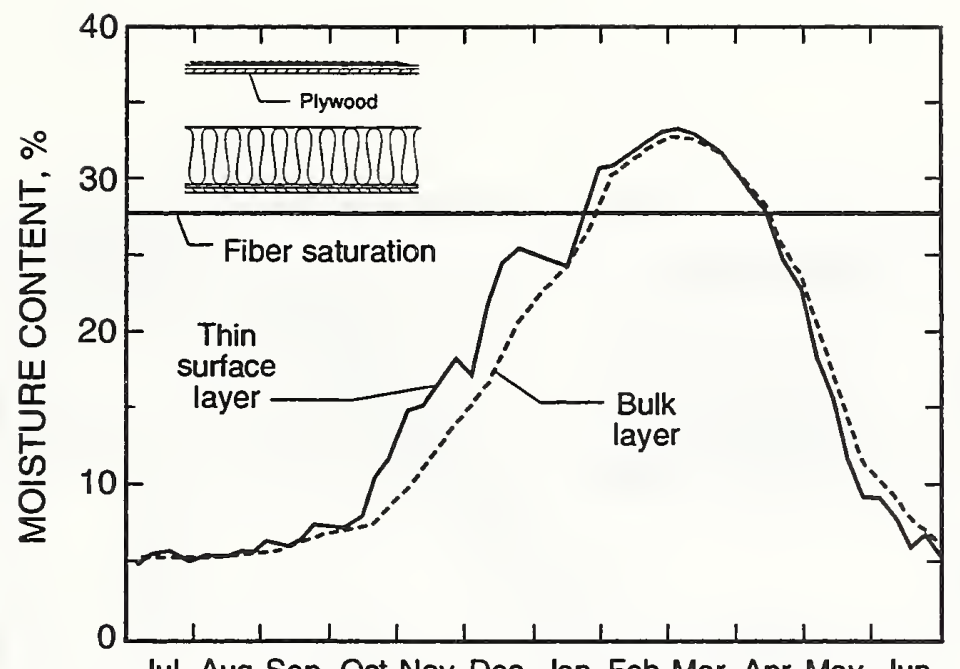

Jul Aug Sep Oct Nov Dec Jan Feb Mar Apr May Jun

TIME OF YEAR

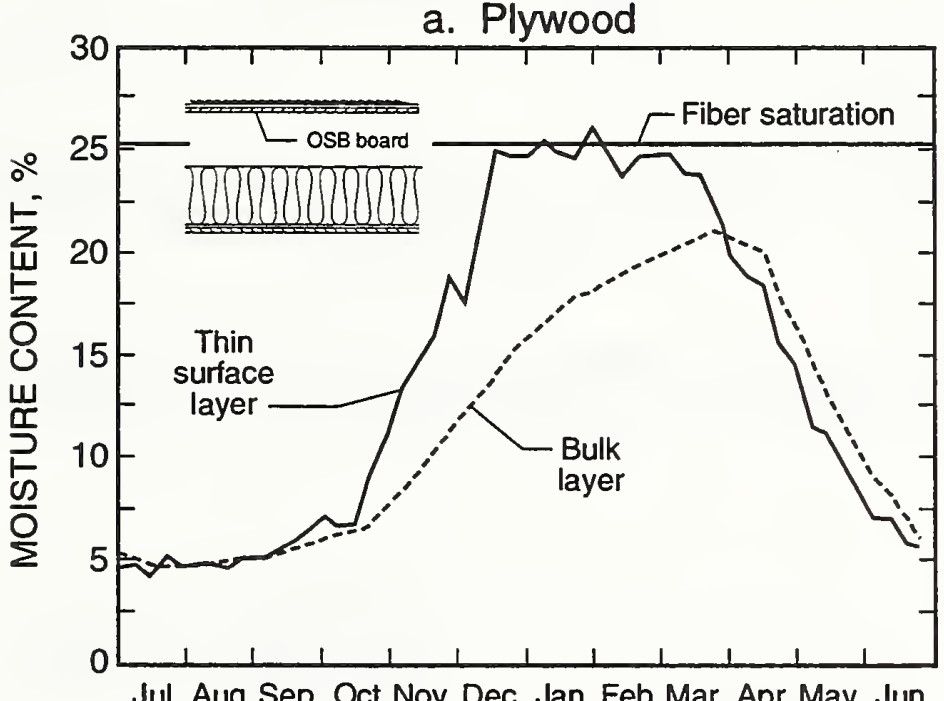

TIME OF YEAR

b. Oriented strand board

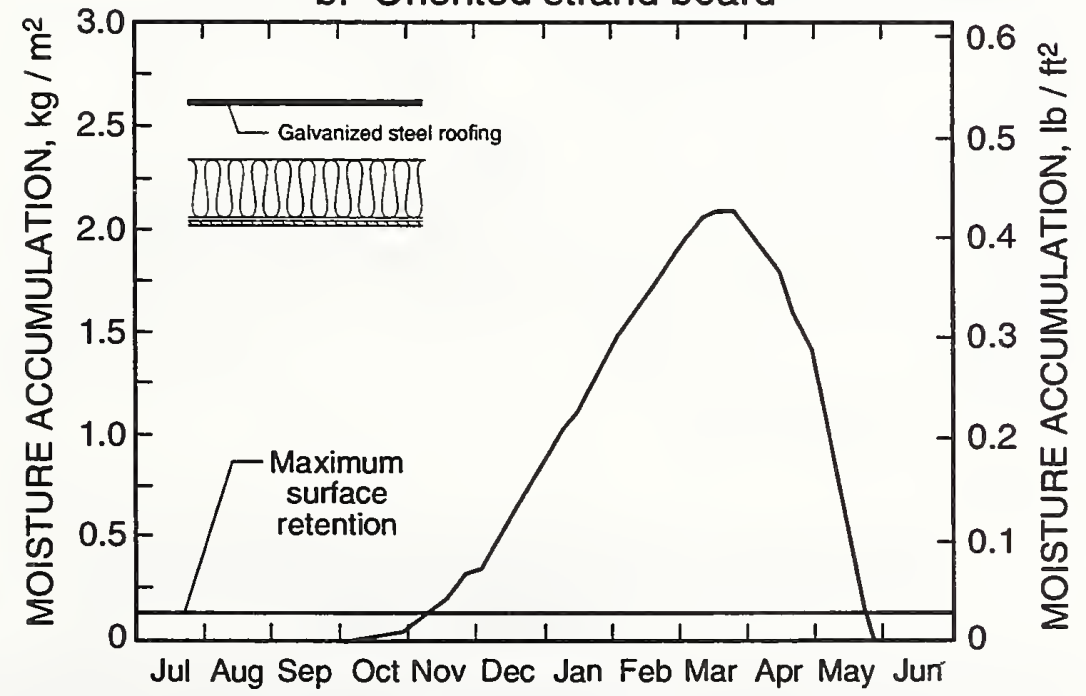

TIME OF YEAR

c. Galvanized steel roofing.

Fig. 15. Moisture accumulation of roof plotted versus time of year for three roof constructions (Madison, WI). 


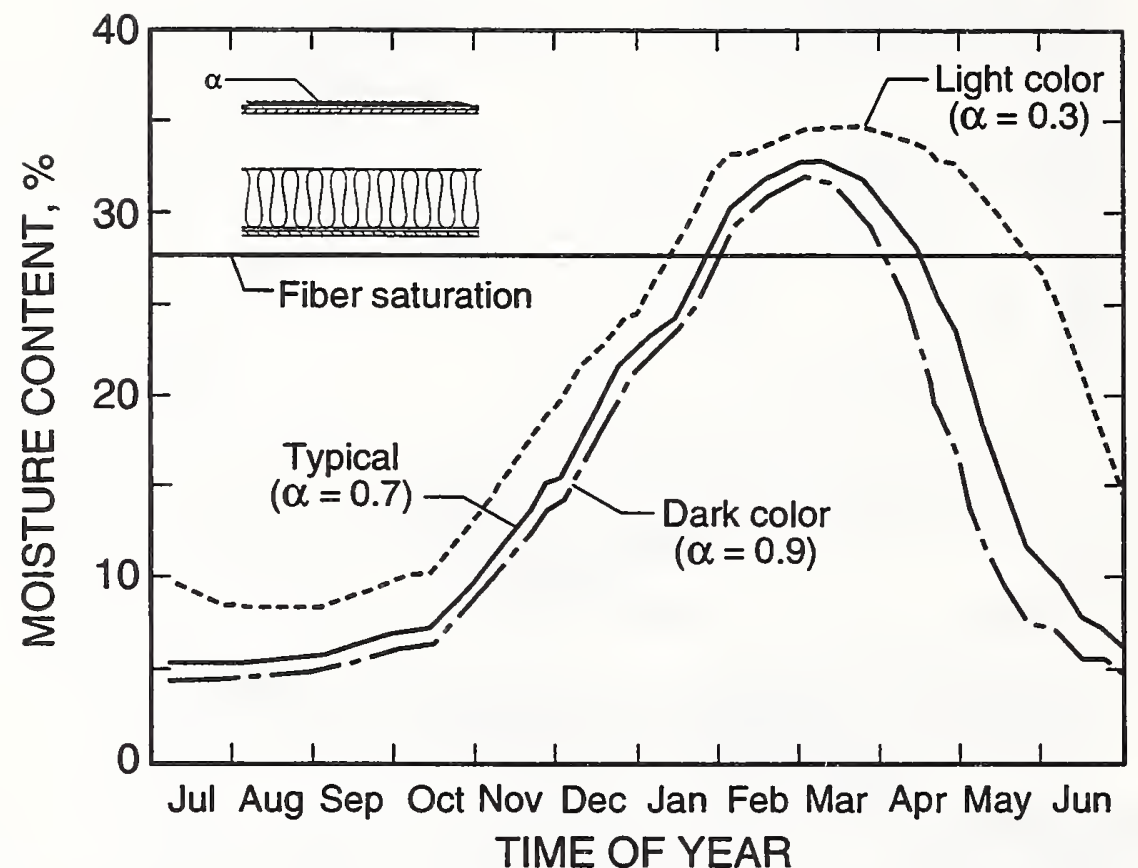

Fig. 16. Moisture content of plywood roof sheathing plotted versus time of year for three solar absorptances(Madison, WI).

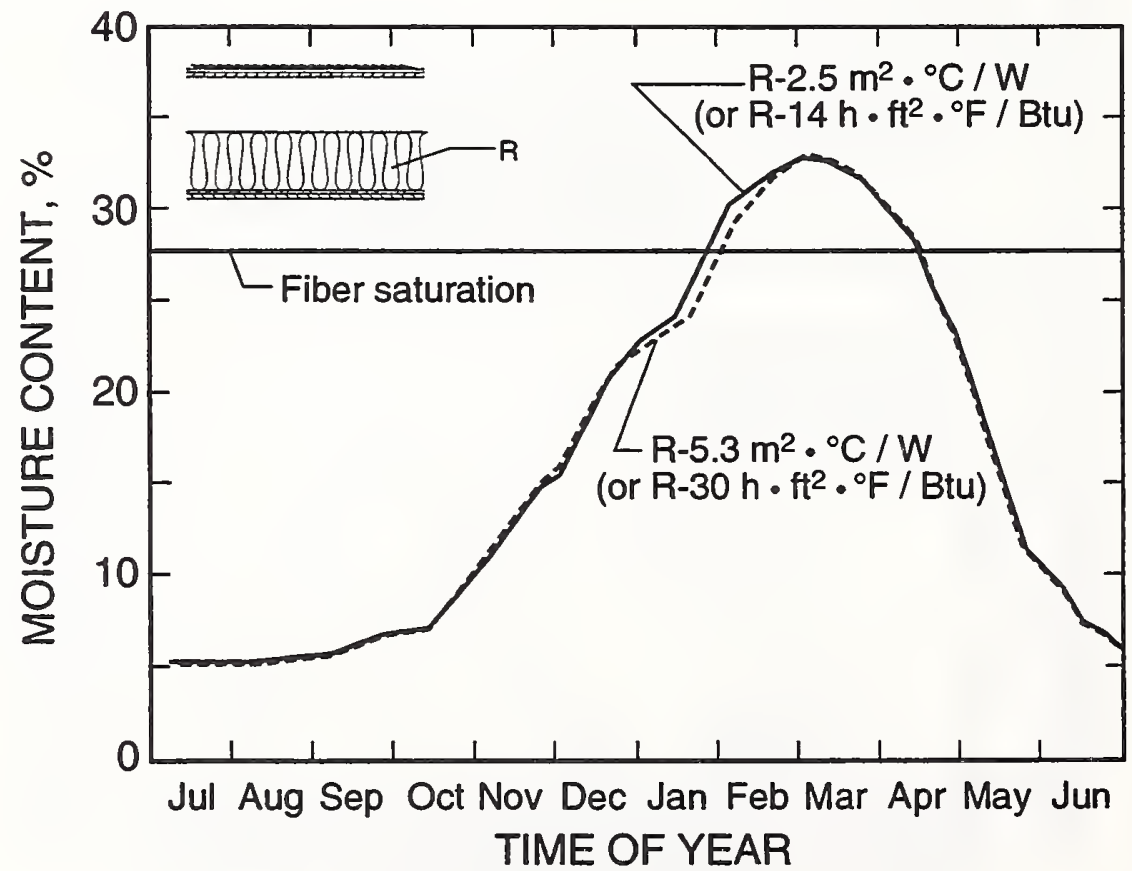

Fig. 17. Moisture content of plywood roof sheathing plotted versus time of year for two insulation levels (Madison, WI). 
占

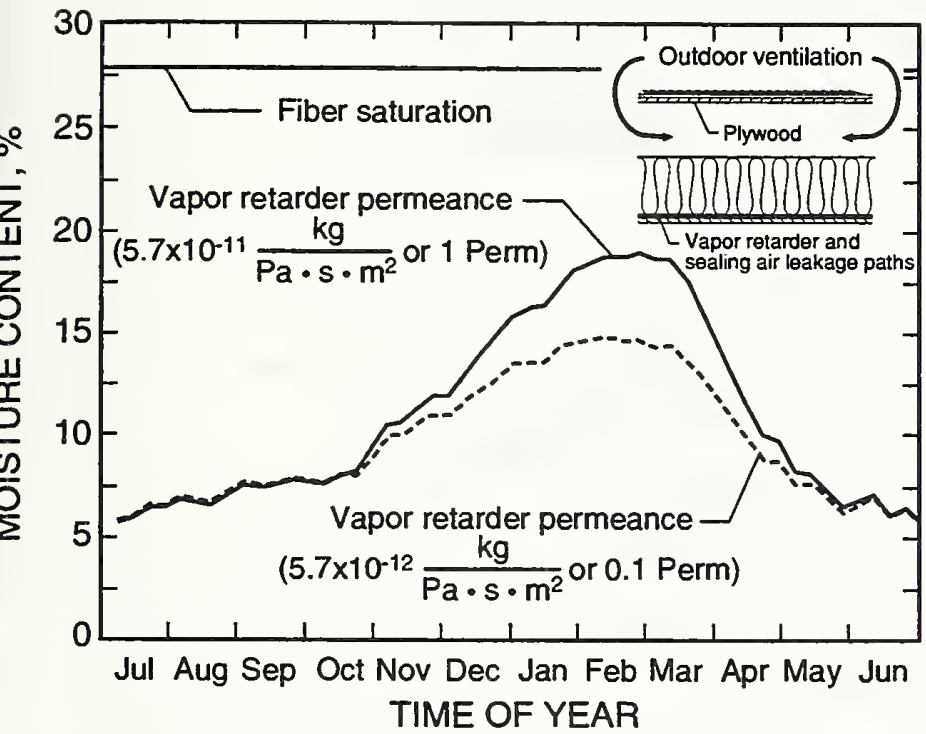

Jul Aug Sep Oct Nov Dec Jan Feb Mar Apr May Jun TIME OF YEAR

a. Madison, WI

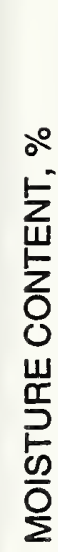

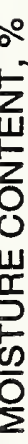

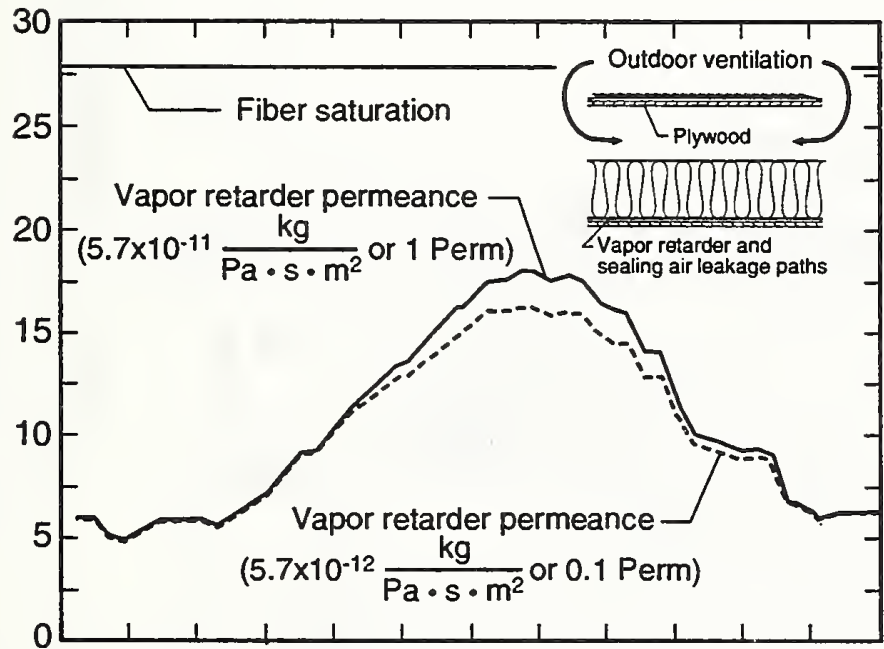

Jul Aug Sep Oct Nov Dec Jan Feb Mar Apr May Jun TIME OF YEAR

c. Portland, OR

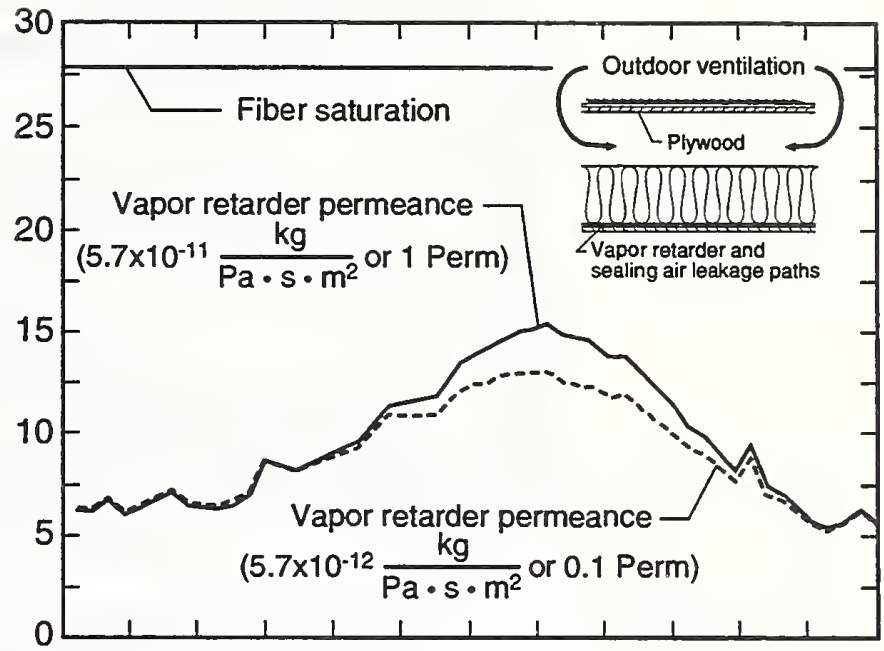

Jul Aug Sep Oct Nov Dec Jan Feb Mar Apr May Jun TIME OF YEAR

b. Boston, MA

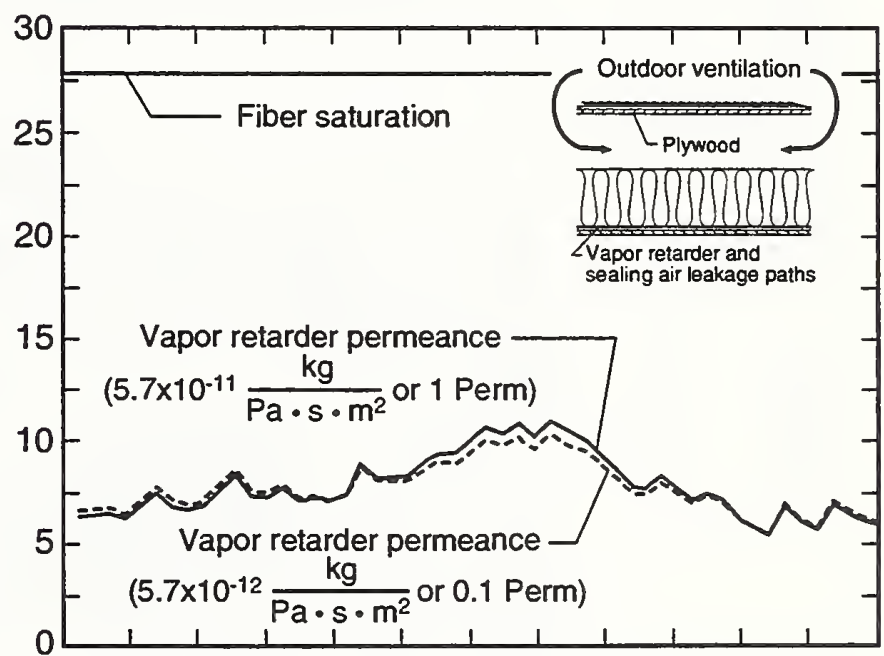

Jul Aug Sep Oct Nov Dec Jan Feb Mar Apr May Jun TIME OF YEAR

d. Atlanta, GA

Fig. 18. Effectiveness of recommended practices for plywood roof construction (i.e., sealing air leakage paths in the ceiling, naturally ventilating the roof cavity, and providing a ceiling vapor retarder) 
(Madison, WI)

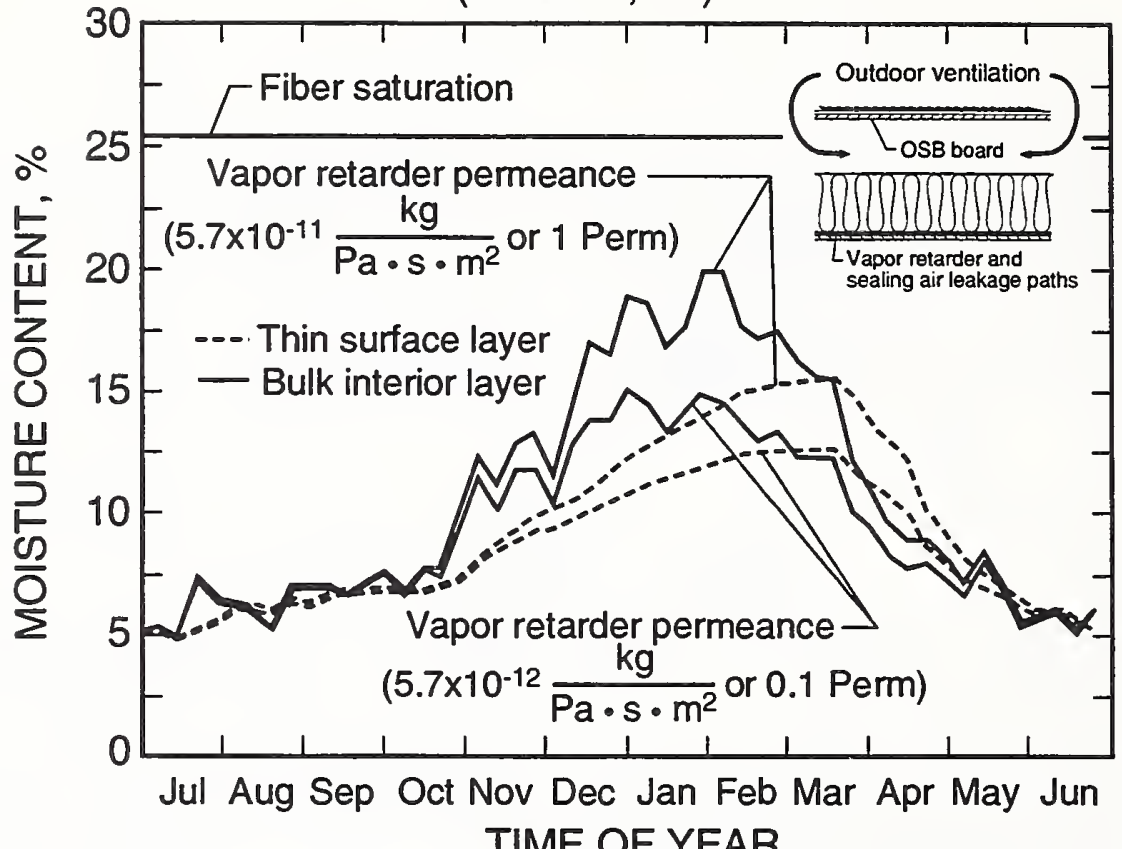

Fig. 19. Effectiveness of recommended practices for OSB roof construction (i.e., sealing air leakage paths in the ceiling, naturally ventilating the roof cavity, and providing a ceiling vapor retarder)

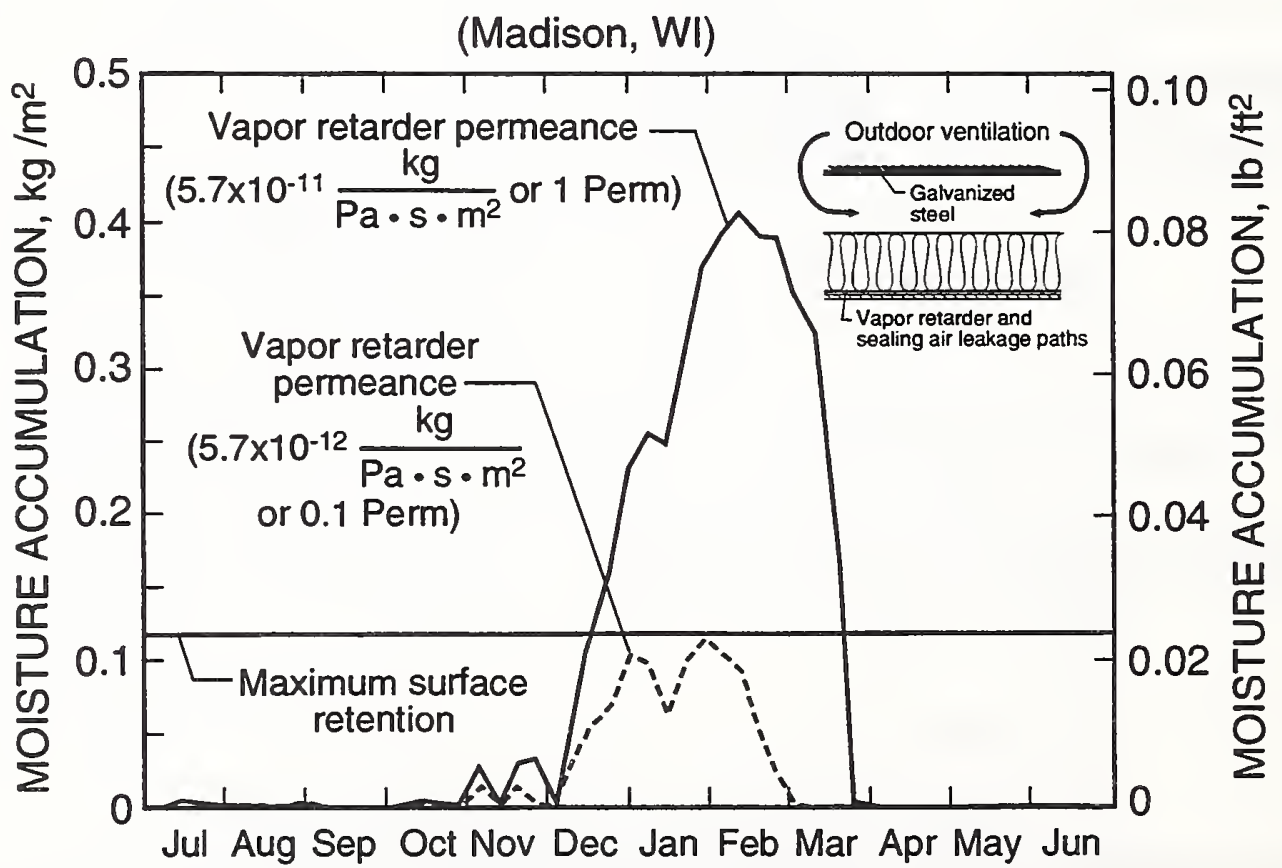

TIME OF YEAR

Fig. 20. Effectiveness of recommended practices for galvanized steel roof construction (i.e., sealing air leakage paths in the ceiling, naturally ventilating the roof cavity, and providing a ceiling vapor retarder) 


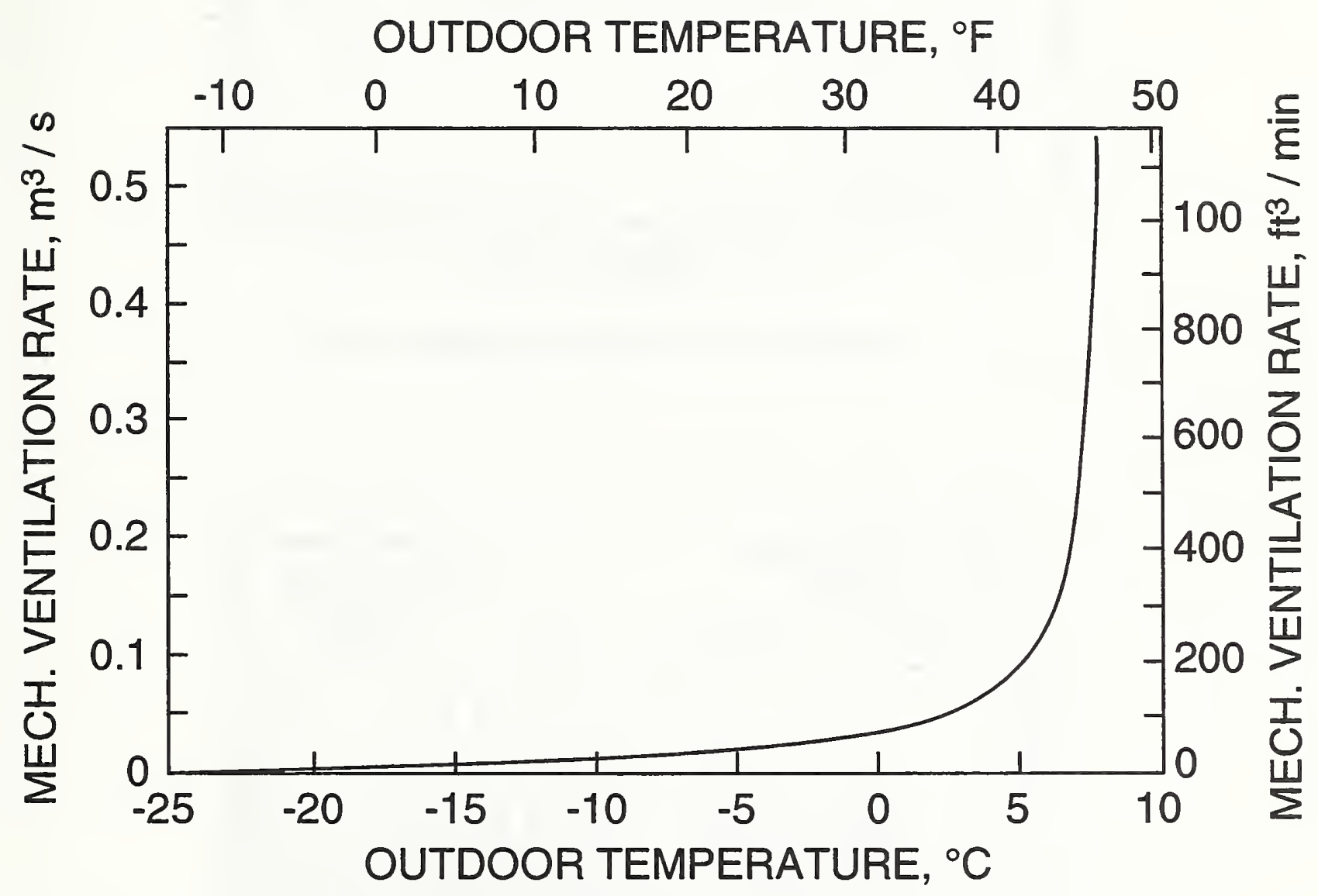

Fig. 21. Required mechanical ventilation rate to maintain an indoor relative humidity of $35 \%$ 


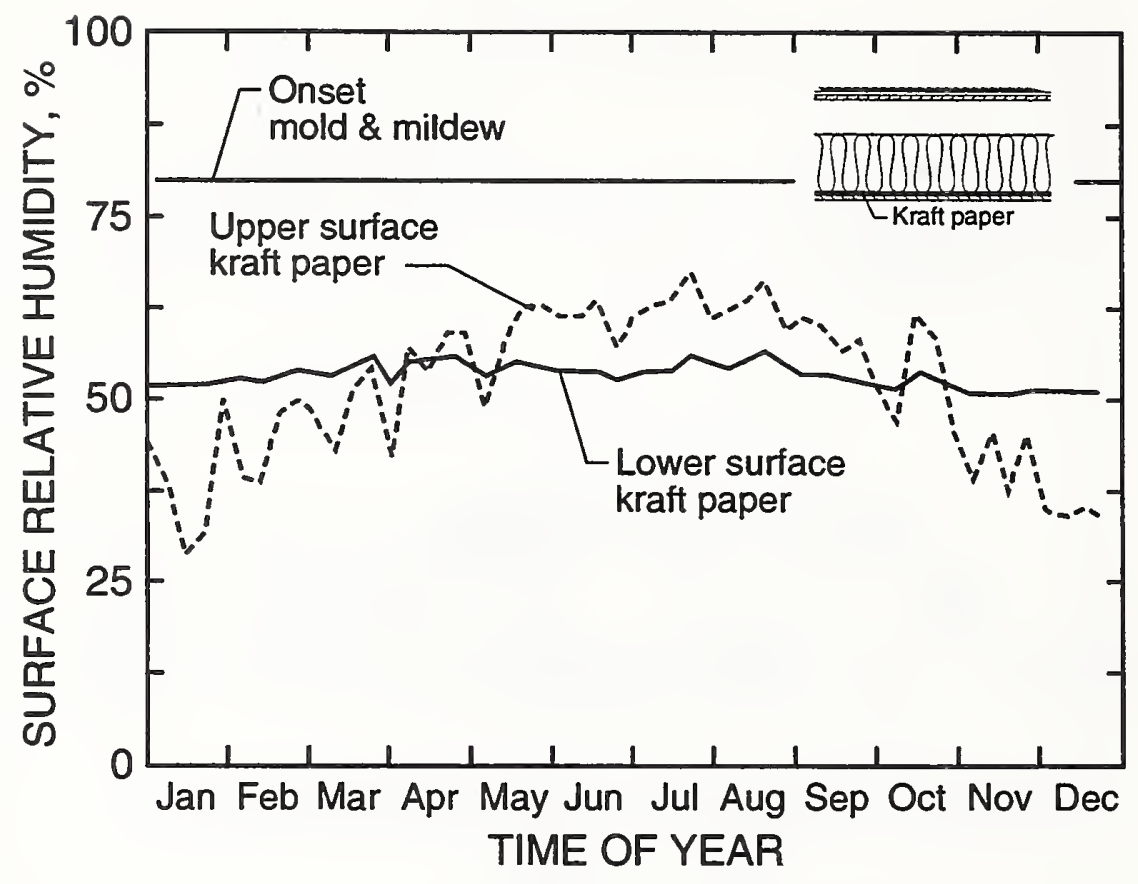

a. Weekly average surface relative humidity

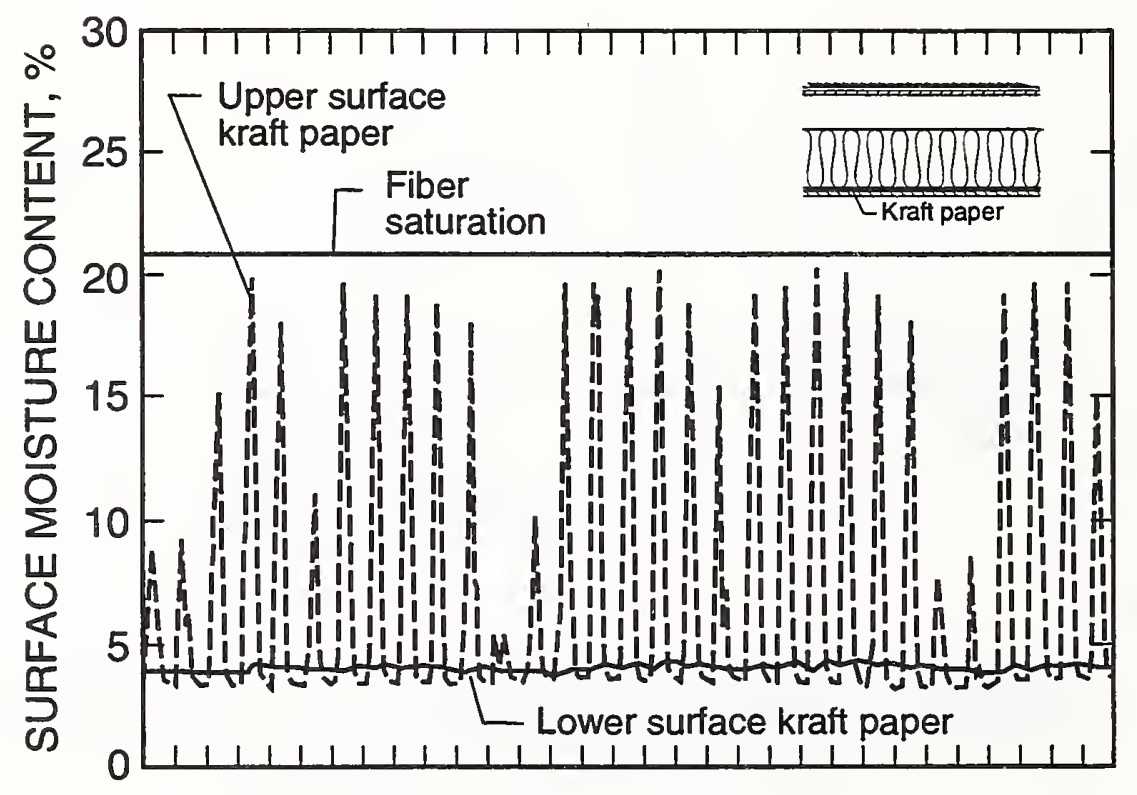

ELAPSED TIME, Days

b. Hourly surface moisture content for July

Fig. 22. Moisture content of kraft paper plotted versus time for baseline construction exposed to hot and humid climate (unvented roof cavity). 


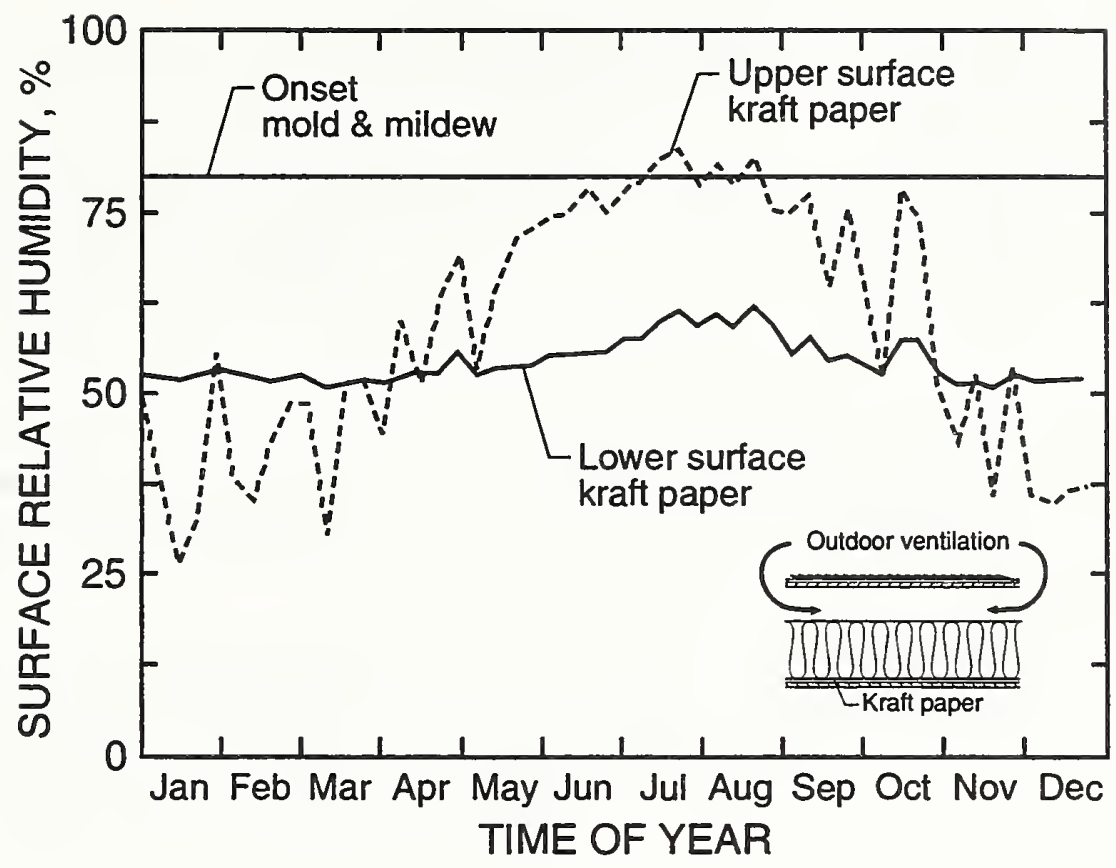

a. Weekly average surface relative humidity

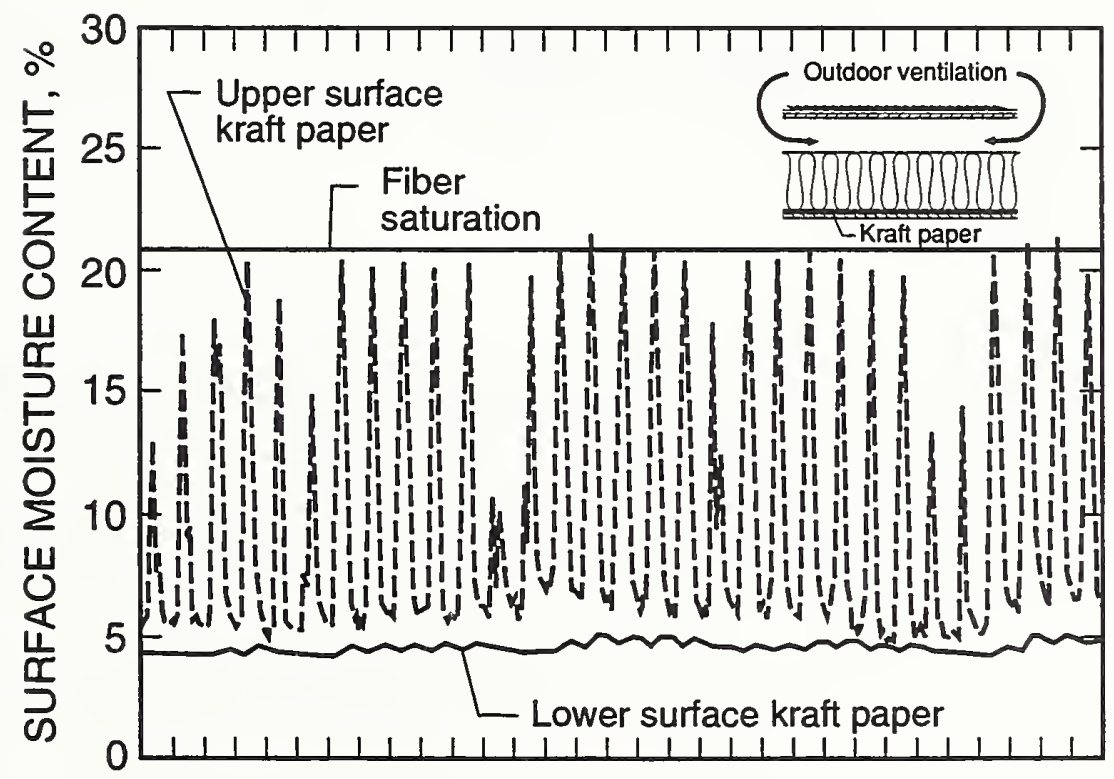

ELAPSED TIME, Days

b. Hourly surface moisture content for July

Fig. 23. Moisture content of kraft paper plotted versus time for baseline construction exposed to hot and humid climate (ventilated roof cavity). 



\begin{tabular}{|lr|}
\hline $\begin{array}{lr}\text { NIST-114 } \\
\text { (REV. 9-92) }\end{array}$ & U.S. DEPARTMENT OF COMMERCE \\
ADMAN 4.09 & NATIONAL INSTITUTE OF STANDARDS AND TECHNOLOGY \\
& MANUSCRIPT REVIEW AND APPROVAL
\end{tabular}

INSTRUCTIONS: ATTACH ORIGINAL OF THIS FORM TO ONE (1) COPY OF MANUSCRIPT AND SEND TO: THE SECRETARY, APPROPRIATE EDITORIAL REVIEW BOARD. TITLE AND SUBTITLE (CITE IN FUL)

Controlling Moisture in the Roof Cavities of Manufactured Housing
(ERB USE ONLY

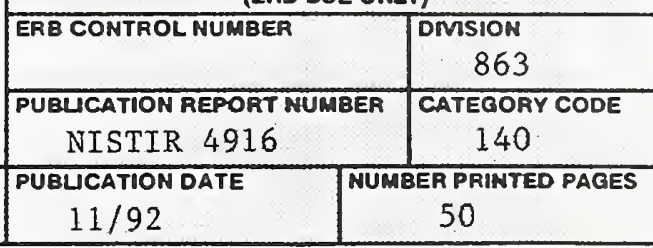

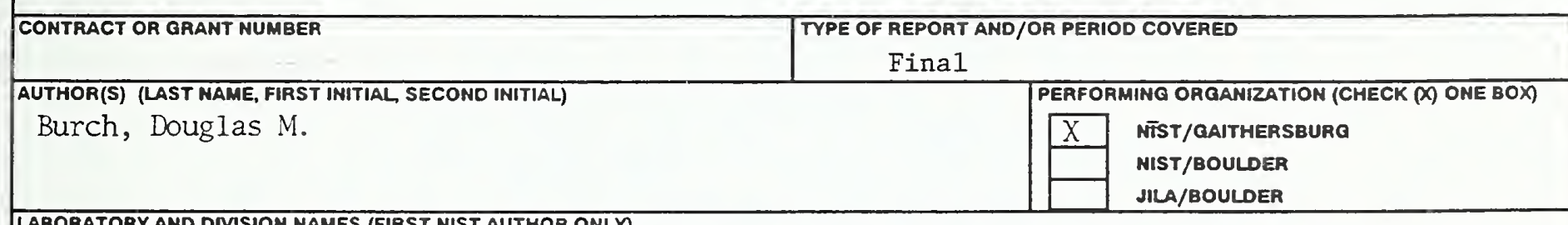

LABORATORY AND DIVISION NAMES (FIRST NIST AUTHOR ONLY)

Building and Fire Research Laboratory, Building Environment Division

SPONSORING ORGANIZATION NAME AND COMPLETE ADDRESS (STREET, CITY, STATE, ZIP)

US Department of Housing and Urban Development

4517 th Street, SW

Washington, D.C. 20410

\section{RECOMMENDED FOR NIST PUBUCATION \\ JOURNAL OF RESEARCH (NIST JRES) \\ J. PHYS. \& CHEM. REF. DATA (JPCRD) \\ HANDBOOK (NIST HB) \\ SPECIAL PUBLCATION (NIST SP) \\ TECHNICAL NOTE (NIST TN)}

RECOMMENDED FOR NON-NIST PUBLICATION (CITE FULLY

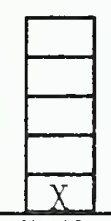

MONOGRAPH (NIST MN) NATL STD. REF. DATA SERIES (NIST NSRDS) FEDERAL INF. PROCESS. STDS. (NIST FIPS) UST OF PUBLICATIONS (NIST LP) NIST INTERAGENCY/INTERNAL REPORT (NISTIR)

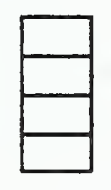

LETTER CIRCULAR BUILDING SCIENCE SERIES PRODUCT STANDARDS OTHER U.S. $\square$ FOREIGN PUBLSHING MEDIUM

PAPER DISKETTE (SPECIFY) OTHER (SPECIFY)

SUPPLEMENTARY NOTES

ABSTRACT (A 1500-CHARACTER OR LESS FACTUAL SUMMARY OF MOST SIGNIFICANT INFORMATION. IF DOCUMENT INCLUDES A SIGNIFICANT BIBUOOGRAPHY OR LITERATURE SURVEY, CITE IT HERE. SPEUL OUT ACRONYMS ON FIRST REFERENCE.) (CONTINUE ON SEPARATE PAGE, IF NECESSARY.)

A detailed computer analysis is conducted to investigate whether moisture problems occur in the roof cavity of manufactured homes constructed in compliance with the current Department of Housing and Urban Development (HUD) Standards for manufactured housing. The current HUD Standards require a ceiling vapor retarder, but do not require outdoor ventilation of the roof cavity. In cold climates, the analysis revealed that moisture accumulates at lower roof surface and poses a risk of material degradation.

The analysis found the following combination of passive measures to be effective in preventing detrimental winter moisture accumulation at lower surface of the roof: 1) providing a ceiling vapor retarder, 2) sealing penetrations and openings in the ceiling construction, and 3 ) providing natural ventilation of the roof cavity.

In addition, the performance of a roof cavity subjected to a hot and humid climate is investigated. The analysis revealed that outdoor ventilation of the roof cavity causes the monthly mean relative humidity at the upper surface of the vapor retarder to exceed $80 \%$. This condition is conducive to mold and mildew growth.

KEY WORDS (MAXIMUM 9 KEY WORDS; 28 CHARACTERS AND SPACES EACH; ALPHABETICAL ORDER; CAPITALZE ONLY PROPER NAMES)

attic ventilation; HUD Manufactured Home Construction and Safety Standards; manufactured housing, mobile homes; moisture control guidelines; moisture in attics

\section{AVAILABILITY}

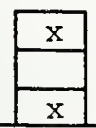

\section{UNLIMITED}

ORDER FROM SUPERINTENDENT OF DOCUMENTS, U.S. GPO, WASHINGTON, D.C. 20402 ORDER FROM NTIS, SPRINGFIELD, VA 22161
NOTE TO AUTHOR(S) IF YOU DO NOT WISH THIS MANUSCRIPT ANNOUNCED BEFORE PUBLICATION, PLEASE CHECK HERE. 

